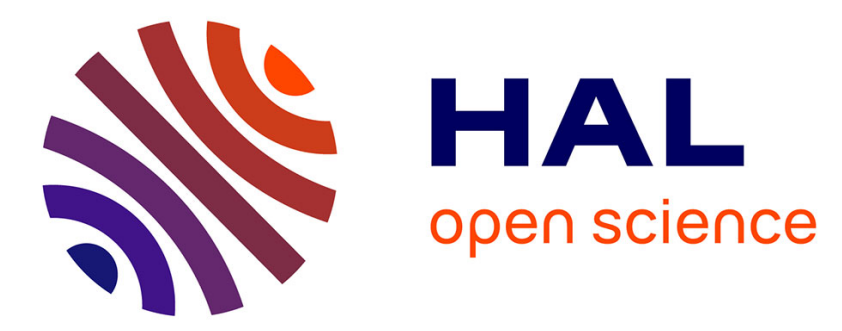

\title{
Experimental investigation of $\mathrm{Ru}$ isotope fractionation between metal, silicate and sulfide melts
}

\author{
Tobias Grützner, Timo Hopp, Jasper Berndt, Arno Rohrbach, Stephan
}

Klemme

\section{- To cite this version:}

Tobias Grützner, Timo Hopp, Jasper Berndt, Arno Rohrbach, Stephan Klemme. Experimental investigation of $\mathrm{Ru}$ isotope fractionation between metal, silicate and sulfide melts. Chemical Geology, 2021, 580, pp.120384. 10.1016/j.chemgeo.2021.120384 . hal-03474539

\section{HAL Id: hal-03474539 \\ https://hal.sorbonne-universite.fr/hal-03474539}

Submitted on 10 Dec 2021

HAL is a multi-disciplinary open access archive for the deposit and dissemination of scientific research documents, whether they are published or not. The documents may come from teaching and research institutions in France or abroad, or from public or private research centers.
L'archive ouverte pluridisciplinaire HAL, est destinée au dépôt et à la diffusion de documents scientifiques de niveau recherche, publiés ou non, émanant des établissements d'enseignement et de recherche français ou étrangers, des laboratoires publics ou privés. 


\section{Experimental investigation of $\mathrm{Ru}$ isotope fractionation between metal,}

2

3

4 Tobias Grützner ${ }^{1,2^{*}}$, Timo Hopp ${ }^{3,4}$, Jasper Berndt ${ }^{2}$, Arno Rohrbach ${ }^{2}$ \& Stephan Klemme ${ }^{2}$

$5{ }^{1}$ Institut de minéralogie, de physique des matériaux et de cosmochimie, Sorbonne Université, 4, Place

6 Jussieu - BC 115 - 75252 Paris Cedex 5, France.

$7 \quad{ }^{2}$ Institut für Mineralogie, Westfälische Wilhelms Universität Münster, Corrensstrasse 24, 48149

8 Münster, Germany.

9

\section{Abstract}

\section{silicate and sulfide melts}

${ }^{3}$ Origins Laboratory, Department of the Geophysical Sciences and Enrico Fermi Institute, The University of Chicago, 5734 South Ellis Avenue, Chicago, IL 60637, USA.

${ }^{4}$ Institut für Planetologie, Westfälische Wilhelms Universität Münster, Wilhelm-Klemm-Straße 10, 48149 Münster, Germany.

${ }^{*}$ Corresponding author Email addresses: tobias.grutzner-handke@sorbonne-universite.fr (T. Grützner), hopp@uchicago.edu (T. Hopp), jberndt@wwu.de (J. Berndt), arno.rohrbach@wwu.de (A. Rohrbach), stephan.klemme@wwu.de (S. Klemme).

To improve the understanding of large-scale planetary processes, i.e. differentiation and core formation, of Earth and other planetary bodies, we performed experiments at $1 \mathrm{GPa}$ in a range of 
temperatures to investigate mass-dependent isotope fractionation of ruthenium $(\mathrm{Ru})$ between metal, silicate, and sulfide melts. Metal silicate fractionation is ${ }^{102} \mathrm{Ru} /{ }^{99} \mathrm{Ru}_{\text {silicate }}-{ }^{102} \mathrm{Ru} /{ }^{99} \mathrm{Ru}$ metal $=0.02 \pm 0.02$ $\%$ (95\% confidence interval) at $1600{ }^{\circ} \mathrm{C}$ and therefore negligible for Earth's core formation. However, there is resolvable $\mathrm{Ru}$ isotope fractionation between liquid metal and liquid sulfide: The ${ }^{102} \mathrm{Ru} /{ }^{99} \mathrm{Ru}$ ratio of liquid sulfide is $0.11 \pm 0.03 \%$ lighter than that of liquid metal at $1400{ }^{\circ} \mathrm{C}$ in sulfur (S)-bearing experiments. The unexpected lighter Ru isotope composition of the sulfide can be best explained with different Ru-S bonding environments. Our results show furthermore, that addition of tin (Sn) instead of $\mathrm{S}$ to experimental charges affects $\mathrm{Ru}$ isotope fractionation significantly. The ${ }^{102} \mathrm{Ru} /{ }^{99} \mathrm{Ru}$ ratios in the Sn-bearing phase are $0.18 \% \pm \pm 0.01 \%$ heavier than metal; hence, the presence of Sn not only changes the magnitude of the $\mathrm{Ru}$ isotope fractionation but also its direction. The observed $\mathrm{Ru}$ isotope fractionations are too small to preserve a resolvable isotope fractionation signature during core formation or the Hadean matte scenario at very high temperatures.

\section{Introduction}

Planetary core formation, i.e., the segregation of a metal core from a molten silicate mantle is one of the most fundamental processes during planetary differentiation. The highly siderophile elements ( $H S E-R u, R h, P d, R e, O s, I r, P t, A u$ ) are expected to strongly partition into Earth's metallic core during its formation. However, the partitioning behavior of some HSE may depend on the conditions of core formation. Many experimental studies determined metal-silicate partition coefficients for the HSE and suggest that Earth's mantle should have been left more depleted in most HSEs than it is actually observed (e.g. O'Neill et al., 1995; Borisov and Palme, 2000; Holzheid et al., 2000; Fortenfant et al., 2003; Ertel et al, 2008; Mann et al., 2012). Moreover, the relative chondritic HSE abundances inferred for Earth's mantle cannot easily be explained with metal-silicate partitioning. This discrepancy between the expected and actual HSE abundances in Earth's mantle led to the 'late veneer hypothesis' which invokes a late accretion of chondritic material to Earth's mantle after core formation ceased (e.g., Kimura et al., 1974; Wänke 1981; Walker et al., 2015). In consequence, the elemental and isotopic 
composition of the HSE in the Earth's mantle should reflect predominantly the composition of the material that was added after core formation.

A promising tool to better understand core formation and late accretion is stable isotope fractionation during core formation: Recent experimental and theoretical studies have shown that stable isotopes of several elements, e.g. $\mathrm{Cr}$, $\mathrm{Fe}, \mathrm{Mo}$, Si and $\mathrm{Sn}$, are significantly fractionated between liquid metal and silicate phases (e.g. Roskosz et al., 2006; Georg et al., 2007; Roskosz et al., 2009; Moynier et al., 2011; Shahar et al., 2011; Hin et al., 2012, 2013, 2014; Shahar et al., 2015; Bourdon et al., 2018). Mass dependent isotope fractionation of an element is controlled by differences in the bonding environment of the element in different phases (Bigeleisen and Mayer, 1947; Urey, 1947); therefore, stable isotope fractionation is often observed due to different oxidation states or coordination of the element in different phases (Bourdon et al., 2018). As the magnitude of equilibrium isotope fractionation is strongly dependent on temperature $\left(\sim 1 / T^{2}\right)$ (Bigeleisen and Mayer, 1947; Urey, 1947), stable isotope data may be useful to constrain the temperature of metal-silicate equilibration and therefore improve our understanding of core formation processes (review about various isotopic systems and methods in Bourdon et al., 2018). The isotope fractionation factor can potentially be calculated ab-initio from vibrational frequencies of the isotopes in different phases (Bigeleisen and Mayer, 1947; Urey, 1947), but as these remain poorly constrained for most elements, high-pressure high-temperature experiments have been employed to determine mass-dependent stable isotope fractionation between metal and silicate phases (Roskosz et al., 2006; Georg et al., 2007; Roskosz et al., 2009; Shahar et al., 2011; Hin et al., 2012, 2013, 2014; Shahar et al., 2015).

In this study, we conducted experiments to investigate mass-dependent Ru isotope fractionation between liquid metal and liquid silicate. Ru plays an important role in the understanding of late accretion: e.g. natural peridotites show elevated Ru/Ir relative to chondrites (Becker et al., 2006; Day et al., 2017). So far, this was either explained by the addition of a fractionated iron meteorite-like component during late accretion (Fischer-Gödde and Becker, 2012), or by sulfide segregation during Earth's core formation, as Ru is less chalcophile than Ir or other HSE at high pressure and high 
temperature (Laurenz et al., 2016; Rubie et al., 2016). However, the process that caused elevated Ru/Ir has not yet been identified. Hopp and Kleine (2018) compared the mass-dependent Ru isotopic signatures of chondrites, iron meteorites, and terrestrial peridotites and concluded that the bulk silicate Earth (BSE) has a chondritic mass-dependent Ru isotope signature and fractionated iron meteorite components could not have been added during late accretion. Furthermore, the observation of a chondritic Ru isotopic composition of the BSE predicts that core formation processes did not induce measureable Ru isotope fractionation in Earth's mantle prior to the addition of a chondritic late veneer (Hopp and Kleine, 2018). However, experimental constraints on the direction and magnitude of $\mathrm{Ru}$ isotope fractionation between metal and silicate are required to evaluate if any significant amount of Earth's mantle Ru could derive from pre-late veneer processes, i.e. core formation or sulfide segregation. In detail, experimental proof of significant Ru isotope fractionation during core formation processes would, in combination with the chondritic Ru isotopic composition of the BSE, exclude any contribution of such isotopically fractionated pre-late accretion Ru to Earth's mantle HSE budget.

Experiments of this study were designed to study Ru isotope fractionation between metal and silicate. As we will show below, many Ru isotope analyses of silicate phases in this study are dominated by the formation of sulfide nuggets caused by the experimental setup, hence, display metal-sulfide isotope fractionation instead of metal-silicate fractionation. The interaction of metal and sulfide affects HSE during differentiation of planetary bodies, i.e. partial melting and core crystallization, and can therefore give insights into the evolution of two meteorite groups: (1) Magmatic iron meteorites are remnants of asteroidal cores that underwent fractional crystallization (e.g. Scott, 1972; Scott and Wasson, 1975). Hopp et al. (2018) showed that with progressive fractional crystallization the crystallizing solids become isotopically heavier. This can be explained either by the extraction of isotopically lighter Ru in early formed S-poor solids that led to increasingly heavier isotopic composition in the remaining S-rich melt or by a kinetic effect during fractional solidification of the metallic melt. (2) The HSE systematics of samples from partial differentiated asteroids, i.e. primitive achondrites, are controlled by interaction of metal and sulfide phases that form during the early stages 
of differentiation (e.g. Goodrich et al., 2013; Keil, 2014; Keil and McCoy, 2018). Hence, experimental constraints on Ru isotope fractionation between metal and sulfide potentially can provide insights into early differentiation processes.

\section{Methods}

\subsection{Starting Materials}

The starting material was prepared from analytical grade oxides $\left(\mathrm{SiO}_{2}, \mathrm{Al}_{2} \mathrm{O}_{3}, \mathrm{MgO}, \mathrm{FeO}\right)$, carbonates $\left(\mathrm{CaCO}_{3}, \mathrm{Na}_{2} \mathrm{CO}_{3}, \mathrm{~K}_{2} \mathrm{CO}_{3}\right)$, pure $\mathrm{S}$ and metals $(\mathrm{Fe}, \mathrm{Sn}, \mathrm{Ru})$. To release absorbed water and unwanted hydroxides, $\mathrm{MgO}$ was fired in a Pt-crucible to $1000^{\circ} \mathrm{C}$ for at least $2 \mathrm{~h}$ and it was subsequently stored in a drying oven at $110^{\circ} \mathrm{C}$. The starting material compositions are listed in Table 1 . We always used the same batch of Ru powder for the preparation of all starting materials. Silicate as well as metal powders were mixed separately in agate mortars under acetone for at least 30 min to obtain fine grained and homogenous starting material mixtures.

The silicate starting material was first prepared without Fe. This Fe-free mixture of oxides and carbonates was vitrified in a Pt crucible at $1500^{\circ} \mathrm{C}$ for $2 \mathrm{~h}$ to release all $\mathrm{CO}_{2}$ from the starting material. The glass was reground under acetone and $\mathrm{FeO}$ was subsequently added to the silicate starting powder.

As Ru partition coefficients can easily exceed values of 10000 (Laurenz et al., 2016), extremely low Ru concentrations are expected for the silicate glass. Therefore, 10 to $11 \mathrm{wt} . \%$ Ru was added to the metal phase starting material. Assuming a metal-silicate ratio of 1:10 and a $D_{\mathrm{Ru}}{ }^{\text {metal-silicate }}$ of 10000 , this results in a silicate glass with $1.1 \mu \mathrm{g} / \mathrm{g} \mathrm{Ru}$.

\subsection{Experimental techniques}

The starting material was pressed into either MgO single crystal or graphite capsules (Schunk, Germany). MgO capsules were drilled out of $10 \mathrm{~mm}^{3}$ synthetic $\mathrm{MgO}$ single crystal cubes in the technical 
workshops at the Institute for Mineralogy at WWU Münster. In order to maximize the capsule size and the amount of silicate glass in the run products, the capsule size was set to $6 \mathrm{~mm}$ O.D., $4 \mathrm{~mm}$ I.D., with an inner length of about $6 \mathrm{~mm}$ and a $2 \mathrm{~mm}$ thick bottom. The capsuled was closed by a $2 \mathrm{~mm}$ thick lid of the same capsule material.

Silicate and metal starting material powders were pressed into the capsule in separate layers with a volume ratio of about $90 \%$ silicate and $10 \%$ metal. For most of the experiments, the metal layer was placed on top of the silicate powder to ensure that the metal melt sinks through the entire column of silicate melt during the experiment. However, to test for any effect of the metal location in the capsule before the runs on isotope fractionation, several experiments were performed where the metal powder was located at the bottom of the capsule, and other runs (e.g. E017) contain starting materials where metal and silicate mixtures where homogenously mixed (Table 3).

All experiments were conducted in an end-loaded piston cylinder apparatus at the University of Münster using $1 / 2 "$ piston cylinder assemblies consisting of concentric cylinders of talc, pyrex glass and a thin graphite heater (Klemme et al. 1997). The inner crushable alumina parts of our usual pistoncylinder assemblies (e.g. Gervasoni et al., 2017; Grützner et al., 2017) were replaced completely by the single crystal MgO capsules or were reduced to $0.5 \mathrm{~mm}$ thickness when graphite capsules were used. This modification of the piston cylinder assembly allows experiments at relatively high pressures and provides enough material in a single experimental run for $\mathrm{Ru}$ isotope analyses. Temperatures were monitored and controlled with $\mathrm{W}_{97} \mathrm{Re}_{3}-\mathrm{W}_{75} \mathrm{Re}_{25}$ thermocouples and a Eurotherm-controller (Schneider Electric).

The experimental run durations ranged from 2 to $6 \mathrm{~h}$. The experiments were run for a minimum of $2 \mathrm{~h}$ to achieve chemical and isotopic equilibrium between liquid metal and liquid silicate. This is commonly achieved in minutes to < 2h (e.g. Poitrasson et al., 2009; Shahar et al., 2011; Hin et al., 2012, 2013, 2014; Bourdon et al., 2018) for related systems. Sample E098 and E102 show the same isotope fractionation values within the error for $2 \mathrm{~h}$ and $6 \mathrm{~h}$ which shows that isotopic equilibrium is reached at 
least for $1600{ }^{\circ} \mathrm{C}$ in less than $2 \mathrm{~h}$. The same is the case for $<3 \mathrm{~h}$ at $1300{ }^{\circ} \mathrm{C}$ (sample E104 and E128).

150 However, given the case of isotopic disequilibrium in a certain experiment we would expect higher

151 fractionation than at equilibrated conditions. As we will show in the Discussion, fractionation is small.

152 It would then become even smaller at equilibration without changing the proposed implications of this

153 study. The run duration was not longer than $6 \mathrm{~h}$ to avoid any Soret effect that may cause isotope

154 fractionation along the temperature gradient of the piston cylinder capsule but would normally require

155 several tens of hours run duration (Kyser et al., 1998; Richter et al., 2008).

156

157

158

159

160

161

162

163

164

165

166

167

168

169

170

171

172

173
As equilibrium isotope fractionation strongly depends on temperature and decreases significantly with increasing temperature, experiments were performed between 1300 and $1600{ }^{\circ} \mathrm{C}$. The lower temperature limit was set by the liquidus temperature of the metal phase and the upper limit by the technical limitations of the piston cylinder, hence by the amount of needed material. In order to lower the liquidus of the metal phase, Sn was added to the metal phase in the first runs (c.f. Hin et al., 2013). However, Young et al. (2015) and Shahar et al. (2015) argue that addition of Sn to the metal might affect the isotopic fractionation. Therefore, we replaced Sn by S in other runs, or we used a mixture of both $\mathrm{S}$ and $\mathrm{Sn}$ (Table 1).

The experimental run products were either mounted in epoxy or acrylic resin for electron microscopy, electron microprobe, and Laser ablation inductively coupled mass spectrometry measurements, or the capsules were carefully crushed in an agate mortar for Ru isotope analysis. Due to the material loss during mounting, cutting, and polishing the mounted samples had not enough material for successful further Ru isotope analyses. Therefore, most samples were either mounted for element concentration analyses with the techniques mentioned above, or they were prepared for isotope analysis.

For isotope analysis the silicate glass was separated from the capsule rim and from the metal both using hand picking and magnetic separation. If possible, a representative but randomly picked piece of silicate glass was chosen to be mounted in epoxy resin for additional elemental analysis using EPMA and LA-ICPMS (Table 2). 
Experiment E135 was first mounted in epoxy for element concentration analysis. Afterwards, a small

175 core $(<4 \mathrm{~mm})$ of the silicate glass was drilled out. The capsule walls with attached remaining silicate 176 glass were cut in several cross sections to study Ru concentrations inside the capsule and metal, as

177 well as sulfide nugget distribution along the capsule walls.

178

179

180

181

182

183

184

185

186

\subsection{Major element analysis}

The experimental run products were first characterized by optical microscopy, followed by scanning electron microscope imaging and energy-dispersive X-ray spectroscopy (EDS) analysis (JEOL 6510LA).

To quantify major and minor element concentrations of the experimental products, a JEOL $8530 \mathrm{~F}$ electron microprobe (EPMA) was used. Measurement conditions for wavelength-dispersive spectroscopy (WDS) were typically $15 \mathrm{keV}$ acceleration voltage, $5 \mathrm{nA}$ beam current and usually $10 \mu \mathrm{m}$ beam diameter to receive representative analyses. Standards were pure metals for metal composition and synthetic silicates and oxides for the basaltic glass. $\mathrm{S}$ was standardized on pyrite for metals and on celestine for silicates, respectively. Due to a potential peak shift, peak searches were done for $\mathrm{S}$ before the analysis. Ru concentrations in silicates were always below the detection limit.

Investigations of the observed nanonuggets were conducted using semi-quantitative EDS element mapping in and quantitative WDS analysis. As for the small droplet size of $\leq 400 \mathrm{~nm}$ the accelerating voltage was set to 7kV. At such conditions Monte-Carlo simulations (Drouin et al., 2007) show a lateral resolution of about $400 \mathrm{~nm}$ enabling quantitative analyses of the few larger $400 \mathrm{~nm}$ sized melt droplets. However, as revealed by apparent Si concentrations of about $5 \mathrm{wt} . \%$ a small portion of the surrounding silicate glass has also been excited.

WDS analyses were performed in two steps. Firstly, all elements except Ru and Sn were analyzed with a beam current of $15 \mathrm{nA}$ and counting times of $15 \mathrm{~s}$ on the peak and $5 \mathrm{~s}$ on the background. Secondly, the same spots were measured for Ru and $\mathrm{Sn}$ at $100 \mathrm{nA}$ and counting times of $80 \mathrm{~s}$ on the peak and 40 s on the background. Finally, both analyses were merged using the Offline-matrix correction provided

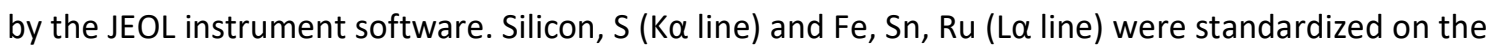
large metal phase within the same sample (10 $\mu \mathrm{m}$ spot size) to avoid variations in carbon coating 
thickness. The metal phase elemental composition had been quantified before under "normal" conditions as described above.

202

203

204

205

206

207

208

209

210

211

\subsection{Trace elements}

Trace elements were analyzed using a Laser ablation inductively coupled mass spectrometry system (Analyte G2 Excimer laser with a wavelength of $193 \mathrm{~nm}$ coupled to a Thermo Scientific Element $2 \mathrm{HR}$ ICPMS) at the Institute for Mineralogy at WWU Münster. The laser was operated with a repetition rate of $10 \mathrm{~Hz}$ and an energy fluence of $3 \mathrm{~J} / \mathrm{cm}^{2}$ per pulse. Typical spot sizes were $65 \mu \mathrm{m}$. The ablated material was transported to the ICP torch using $\mathrm{He}$ and $\mathrm{Ar}$ as carrier gases with flow rates of $0.13 \mathrm{~L} / \mathrm{min}$. Measurements on the reference material (NIST 612 glass standard) were done at the beginning and end of every session, as well as after about every 30 spots. All analyses were normalized to $\mathrm{FeO}$ concentrations, which had been determined by EPMA analyses. For internal reference and to track any mass bias drift, we used BIR-1G, BHVO-2G, and metal phases from experimental run E017 and E031. The analytical results were processed using the software GLITTER (Griffin et al., 2008).

\subsection{Ruthenium isotope analysis}

The Ru stable isotopic composition of the experimental run products were analyzed following the Ru double spike method described by Hopp et al. (2016). The small sample weights, the large amount of Ru in the metal phases, as well as the contrasting low and unknown Ru concentration of the silicate glass required modification of the procedures that are described in the following paragraph.

\subsubsection{Sample preparation}

After separation of metal and crushing of silicate glasses, the samples were weighed and transferred into Savillex PFA beakers. Metal phases ( $\sim .02$ to $0.05 \mathrm{~g}$ ) were digested using $7.5 \mathrm{ml}$ reverse aqua regia inside sealed Carius tubes at $220^{\circ} \mathrm{C}$ for 2 days (Shirey and Walker, 1995). These metal phases always contain the bulk of the Ru in the experiment ( $10 \mathrm{wt} . \%)$ and hence represent the bulk/initial Ru isotopic compositions of the system. To verify this, an aliquot of the starting material (Alfa Aesar Ru > 99.9\% metal basis powder; 325 mesh, 13994, LOT: R17A033) was digested along with the metals and analyzed 
for its Ru isotopic composition. After digestion, a $1 \mathrm{ml}$ aliquot of the solutions were diluted to $10 \mathrm{ml}$ of $6 \mathrm{M} \mathrm{HCl}$.

The silicate samples ( $\sim 0.06$ to $\sim 0.13 \mathrm{~g}$ ) were digested in PFA vials at $100{ }^{\circ} \mathrm{C}$ for 24 hours using a mixture of double teflon-distilled $\mathrm{HCl}$ and $\mathrm{HF}$ acids ( $4 \mathrm{ml}$ concentrated $\mathrm{HCl}+2 \mathrm{ml} \mathrm{HF}$ ). After digestion, aliquots of the metal and silicate sample solutions were converted to $0.28 \mathrm{M} \mathrm{HNO}_{3}$ and the Ru concentrations in the solutions were determined using a Thermo Scientific $X$-Series 2 quadrupole ICPMS at the Institut für Planetologie, Münster. Based on the calculated Ru concentrations in the individual samples an appropriate amount of $\mathrm{a}^{98} \mathrm{Ru}-{ }^{101} \mathrm{Ru}$ double spike was added. This double spike is used to correct for all analytical fractionation effects; thus, precise determination of the natural mass-dependent isotope fractionation is possible (Rudge et al., 2009). The spiked solutions were equilibrated in closed beakers for 24 hours using reverse aqua regia at $120^{\circ} \mathrm{C}$ on a hotplate. This procedure results in complete spikesample equilibration, as demonstrated for iron meteorites and chondrites (Hopp et al., 2018; Hopp and Kleine, 2018). Additionally, no differences between meteorite samples that were spiked prior or after digestion were observed (Hopp and Kleine, 2018). Furthermore, digestion and sample-spike equilibration of several powder aliquots of a homogeneous $\sim 100 \mathrm{~g}$ powder of the Allende meteorite using the method described above resulted in reproducible and accurate data (Hopp and Kleine, 2018).

\subsubsection{Chemical separation of Ruthenium}

The chemical separation of Ru followed a two-stage ion exchange chromatography procedure based on the method outlined in Hopp and Kleine (2018). After sample-spike equilibration, the solutions were dried down at $100{ }^{\circ} \mathrm{C}$ on a hotplate, converted to chloride form and re-dissolved in $5 \mathrm{ml}$ of $0.2 \mathrm{M} \mathrm{HCl}$. In the first step, the sample solutions were loaded onto cation exchange columns filled with $10 \mathrm{ml}$ precleaned BioRad AG50 W-X8 (100-200 mesh) resin. On these columns, the bulk of the HSE were eluted in a total volume of $14 \mathrm{ml} 0.2 \mathrm{M} \mathrm{HCl}$, while the major elements (i.e., $\mathrm{Fe}$ and $\mathrm{Ni}$ ) remain adsorbed on the resin. Then the Ru fractions were dried down on a hotplate and re-dissolved three times using 5 $\mathrm{ml}$ of $1 \mathrm{M} \mathrm{HF}$. To remove remaining interfering elements ( $\mathrm{Zr}, \mathrm{Mo}, \mathrm{Pd})$ the Ru fractions were dissolved in $7 \mathrm{ml} 1 \mathrm{M} \mathrm{HF}$ and were loaded onto anion exchange columns filled with $2 \mathrm{ml}$ of pre-cleaned BioRad 

adsorbed onto the resin. The final Ru fractions were dried and re-dissolved in $0.5 \mathrm{ml} 0.28 \mathrm{M} \mathrm{HNO}_{3}$. This procedure results generally in pure $\mathrm{Ru}$ fractions with $\mathrm{Mo} / \mathrm{Ru}<0.0005$ and $\mathrm{Pd} / \mathrm{Ru}<0.001$, which are sufficiently low to allow for reliable correction of interferences on ${ }^{98} \mathrm{Ru},{ }^{100} \mathrm{Ru},{ }^{102} \mathrm{Ru}$ and ${ }^{104} \mathrm{Ru}$, i.e. the isotopes used in the double spike inversion (Hopp et al., 2016). The overall yield of the chemical separation of Ru varies between $\sim 60$ and $\sim 90 \%$. The Ru blank is $49 \pm 33 \mathrm{pg} R u(1$ s.d.; $n=5)$ and hence insignificant, given that more than $70 \mathrm{ng}$ Ru was analyzed for each sample.

\subsubsection{Mass spectrometry and data reduction}

The Ru isotope measurements were conducted using a Thermo Scientific Neptune Plus MC-ICPMS at the Institut für Planetologie at University of Münster. Prior to the measurements, the samples were dissolved in $0.28 \mathrm{M} \mathrm{HNO}_{3}$ and were introduced into the mass spectrometer using a CETAC Aridus II desolvating system combined with a $70 \mu \mathrm{l} / \mathrm{min}$ ESI PFA nebulizer. The formation of oxides was monitored as $\mathrm{CeO} / \mathrm{Ce}$ and reduced to $<1 \%$ by the addition of $\mathrm{N}_{2}$ to the sample gas. Sample and standard solutions were measured at $\sim 100 \mathrm{ppb}$ using conventional $\mathrm{Ni} \mathrm{H}$ cones and ion beams were simultaneously collected in static mode for all seven stable Ru isotopes $\left({ }^{96} \mathrm{Ru},{ }^{98} \mathrm{Ru},{ }^{99} \mathrm{Ru},{ }^{100} \mathrm{Ru},{ }^{101} \mathrm{Ru}\right.$, ${ }^{102} \mathrm{Ru},{ }^{104} \mathrm{Ru}$ ) together with ${ }^{97} \mathrm{Mo}$ and ${ }^{105} \mathrm{Pd}$ as interference monitors. Ruthenium masses were measured using Faraday cups connected to $10^{11} \Omega$ feedback resistors and the ion beams at ${ }^{97} \mathrm{Mo}$ and ${ }^{105} \mathrm{Pd}$ were collected using $10^{12} \Omega$ feedback resistors. Spiked sample measurements comprised $50 \times 8.2 \mathrm{~s}$ integrations of the ion beams and consumed $\sim 70 \mathrm{ng} \mathrm{Ru}$. The baselines were measured on peak with $40 \times 4.2 \mathrm{~s}$ integrations on a solution blank prior each measurement.

The Ru isotopic data are reported relative to the composition of an Alfa Aesar standard solution $\left(\mathrm{RuCl}_{3}\right.$; Lot \# 61300952) as follows: 
described in Siebert et al. (2001). Both data reduction schemes were used in this study and yielded

277 identical results. The molar proportions of spike determined with the reduction schemes were used to

278 calculate Ru concentrations in the samples. Furthermore, the data reduction provides the natural

279 fractionation factor $\alpha$, from which the mass-dependent $\mathrm{Ru}$ isotopic composition of a sample is 280 calculated as follows:

281

$\delta^{102 / 99} \mathrm{Ru}_{\text {meas. }}=-1000 \times\left(\alpha_{\text {sample }}-\alpha_{\text {standard }}\right) \times \ln \left(m_{102} / m_{99}\right)$

where $m_{102}$ and $m_{99}$ are the atomic weights of ${ }^{102} \mathrm{Ru}$ and ${ }^{99} \mathrm{Ru}$ and $\alpha_{\text {standard }}$ is the mean composition measured for the spiked Alfa Aesar standard solution in each analytical session. The external reproducibility of the Ru stable isotope measurements was estimated to be $\pm 0.05 \%$ ( 2 s.d.; $n=20$ ) for $\delta^{102 / 99} \mathrm{Ru}$, based on repeated measurements of spiked Ru standard solutions and Ru doped geochemical reference materials (BHVO-2, BCR-2, UB-N) (Hopp et al., 2016) and by seven replicate digestions of an Allende (CV3) chondrite powder (Hopp and Kleine, 2018).

Fractionation factors between metal and silicate or sulfide, respectively $\left(\Delta^{102 / 99} \mathrm{Ru}\right.$ metal-silicate $=$ $\delta^{102 / 99} \mathrm{Ru}$ metal $-\delta^{102 / 99} \mathrm{Ru}_{\text {silicate }}$ ), are calculated based on the average isotopic compositions of eleven metals ( $\delta^{102 / 99} \mathrm{Ru}_{\text {bulk }}$ ) that equals the bulk isotopic composition of the starting material because $>99.99$ $\%$ of Ru is incorporated in the metal phases.

\section{Results}

Representative major element compositions from SEM-EDS and EPMA measurements are listed in Table 2. Samples that were only analyzed by SEM-EDS are marked in Table 2. The Ru isotopic compositions of experimental products together with Ru concentrations in silicates are presented in for the mean values in Table 2 and Table 3. 


\subsection{Textures}

300

301

302

303

304

305

306

307

308

309

310

311

312

313

314

315

316

317

\subsubsection{Silicate phases}

During the experiments, the melt composition changes, as the melt reacts with the MgO capsule and becomes more picritic. Consequently, a thin layer of olivine crystallizes during the run at the contact zone between MgO capsule and melt (Figure 1). The quenched silicate melt is typically glass with no quench crystals or other phases. The experiments at $1600^{\circ} \mathrm{C}$ result in elongated, needle-shaped olivine crystals (Figure 2), caused by rapid dissolution of $\mathrm{MgO}$ in the basaltic melt (Hin et al., 2013). MgO concentrations in silicate glasses at $1600{ }^{\circ} \mathrm{C}$ reach up to $36.4(2) \mathrm{wt} . \%$, whereas in experiments at $\mathrm{T}<$ $1600{ }^{\circ} \mathrm{C}$ the $\mathrm{MgO}$ concentration ranges from 7.5(2) to $15.2(6)$ wt.\% (Table 2).

\subsubsection{Metal blobs, metal droplets and sulfidic nanonuggets}

In successful experiments, a large metal blob is located at the bottom of the capsule after the run. This is independent from the location of the metal powder in the capsule before the run, which was either on top or at the bottom of the capsule (Figure 1a). In experiments with a homogenized starting material (runs E017, E029, E031) several medium-sized blobs (> $10 \mu \mathrm{m}$ ) were found in the capsule attached to the capsule walls (Figure 1a).

Tiny metal droplets $(<10 \mu \mathrm{m})$ are observed at the capsule walls in nearly all experiments (Figure $1 \mathrm{~d}$ ). However, the number of droplets increases, if the metal had been placed at the top of the capsule before the run and sank down to the bottom during the experiment. Droplets attached to the wall can be also found in run products where the metal powder had been placed directly at the bottom.

Large blobs, medium blobs and tiny metal droplets are all assigned to the metal phase during the experimental run and show no variation in chemical composition. Most medium size blobs are attached to the olivines that formed at the capsule rim (Figure 1). Their number can be minimized by placing the starting metal material at the bottom of the capsule.

Beside the aforementioned metal phases, nano-sized $(<1 \mu \mathrm{m})$ nuggets appear in many silicate glasses (Figure 6) and these nuggets have a composition that differs strongly from the metal starting material. 
The analyzed nuggets are all sulfidic and because of their small size could not be separated from the silicate phase. As it will be shown in subsection 4.1.2, these Ru-bearing sulfidic nuggets are in equilibrium with the melts during the experiments and they dominate the budget and isotopic composition of Ru in the silicate portion of the experiments. In the following text, the term 'nugget' hence refers to the sulfidic nanonuggets described above. Any small metal phase of similar size that has a composition identical to the major metal phase in the experiment or any Fe-exsolution phase that formed during quenching, will be labeled as 'droplet'.

In graphite capsule experiments, we did not observe metal droplets attached to the walls or sulfidic nanonuggets. This correlates well with the lack of olivine in experiments with graphite capsules. These results indicate that metal droplets do not stick to the capsule wall itself, but that they tend to attach to surfaces of crystallizing olivines close to the wall of MgO capsules (Figure 1).

\subsection{0xygen fugacity}

The oxygen fugacity was mainly controlled by the reducing starting material components. To get an

$\Delta I W=2 \times \log \left(\frac{X_{F e O} * \gamma_{F e O}}{X_{F e} * \gamma_{F e}}\right)$

where $X_{\mathrm{FeO}}$ and $X_{\mathrm{Fe}}$ are the molar fractions of iron in the silicate and metal melts. $\gamma_{\mathrm{FeO}}$ and $\gamma_{\mathrm{Fe}}$ describe their respective activity coefficients. The activity coefficient for Fe in the metal alloy was calculated using the modified Wagner epsilon formalism (Ma, 2001). Interaction parameters for Sn and S were taken from the steel making literature (JSPS, the 19th Committee on Steelmaking, 1988). The addition of up to $4 \mathrm{wt} . \% \mathrm{~S}$ and/or $23 \mathrm{wt} . \% \mathrm{Sn}$ to the Fe-dominated alloy shows almost ideal behavior. For Ru an ideal approach to Raoult's law was assumed due to the lack of activity data. The calculated values for $\gamma_{\mathrm{Fe}}$ range from 0.995 to 1.067. For $\gamma_{\mathrm{FeO}}$ the value was set to 1.7 after Holzheid et al. (1997), who showed that the activity coefficient of $\mathrm{FeO}$ in a basaltic melt with $\mathrm{MgO}$ between $4-20$ wt.\% and 
FeO up to $12 \mathrm{wt} . \%$ is constant between $1300{ }^{\circ} \mathrm{C}$ and $1600^{\circ} \mathrm{C}$. If we exclude the experiments at $1600{ }^{\circ} \mathrm{C}$ with $\mathrm{MgO}$ concentrations of above $30 \mathrm{wt} . \%$, all other silica glasses from this study are within the aforementioned range (Table 2). In MgO capsules oxygen fugacity vary between $\Delta \mathrm{IW}=-1.86$ and -2.05 .

This is in good agreement with the approximation made by Wade and Wood (2005) for their proposed core formation conditions. In graphite capsules oxygen fugacity is expected to be in a similar range around IW but $\mathrm{fO}_{2}$ could not be calculated in these experiments as the metal phase was lost during sample preparation. In these experiments the metal phase did not form a large metal blob, but instead a metal layer was formed that was also attached to the capsule wall. However, the existence of the metal phase indicates an oxygen fugacity of at least $\Delta \mathrm{IW}<0$ in these runs.

\subsection{Ruthenium concentrations in experimental run products}

Ruthenium concentrations were analyzed with EPMA or SEM-EDS for metal phases and with LA-ICPMS as well as MC-ICPMS for the silicate phases. Results for Ru in metal and silicate analyses are listed in

Table 3. In the metal phases Ru concentrations range from 10.8(2) to 14.0(8) wt.\%. The coexisting sulfide phase from E041 has a Ru element concentration of 0.7(2) wt.\%. Ruthenium concentrations measured with LA-ICPMS in silicate glasses range from $0.02 \mu \mathrm{g} / \mathrm{g}$ to $0.6 \mu \mathrm{g} / \mathrm{g}$. The only exception is sample E029 with a Ru concentration of $8 \mu \mathrm{g} / \mathrm{g}$ in the glass. Where the entire capsule was embedded in epoxy for LA-ICPMS analyses (E017; E135), laser spots were chosen to form a cross section along the capsule from the bottom to the top. No Ru concentration gradient was found in the silicate glass of these samples, and we conclude that Ru is homogeneously distributed in the silicate glass (Figure 3).

MC-ICPMS analyses show generally higher concentrations of Ru in the silicate fractions than LA-ICPMS analyses. This is caused by the (sulfidic) equilibrium nanonuggets, which could not be separated from the silicate phase during preparation (except for experiment E135 - see below). Glasses from graphite capsule experiments have the lowest Ru concentrations measured with MC-ICPMS (7 to $8.2 \mu \mathrm{g} / \mathrm{g}$ ). These concentrations are still higher than the LA-ICPMS data, however, in the range of concentrations determined in the glass of E029. Silicate fractions from MgO capsule experiments have Ru 

orders of magnitude higher than the results from LA-ICPMS.

Most runs were prepared for MC-ICPMS analysis by crushing of the sample and separating the metal from the silicate phase - either by picking or by magnetic separation with a hand magnet. For experiment E135 the entire capsule was mounted in epoxy for EPMA and LA-ICPMS analyses. Laser spots were set on the glass, the capsule walls, on the core of olivine and at olivine rims (Figure 2). The LA-ICPMS data show that the Ru concentrations in the glass and in olivine are extremely low $(<0.1$ $\mu \mathrm{g} / \mathrm{g})$ while at the olivine surface $(>0.1 \mu \mathrm{g} / \mathrm{g})$ and at the capsule rim (>>1 $\mu \mathrm{g} / \mathrm{g})$ the Ru concentrations are elevated (Figure 4a). In the MgO capsule Ru concentrations are below the detection limit. After the LA-ICPMS analyses, the silicate glass was drilled out of the mounted capsule with a miniature core drill to avoid any contamination with capsule material or olivine crystals from the wall. Additionally, the olivine-rich glass at the contact to the metal was separated and the MgO capsule was cut into four different sections (Figure $4 \mathrm{~b}$ ) and analyzed in the same way as described for the glasses. Ru concentrations of all seven samples including the metal phase and a zone of ol-rich glass can be found in Figure 4b. Ru concentrations of the silicate glass are low $(0.4 \mu \mathrm{g} / \mathrm{g})$ and in good agreement with LAICPMS analyses. Besides the metal phase, only the ol-bearing glass $(5.4 \mu \mathrm{g} / \mathrm{g})$ and the lowermost capsule wall close to the metal phase $(158 \mu \mathrm{g} / \mathrm{g})$ show elevated Ru concentrations. The analyzed capsule wall sections show Ru concentrations from $0.04 \mu \mathrm{g} / \mathrm{g}$ to $0.28 \mu \mathrm{g} / \mathrm{g}$ in the three upper sections (B, C, D in Figure 4b). The metal phase contains 14.0(8) wt.\% Ru.

\subsection{Ruthenium isotope compositions}

The Ru isotopic composition of the eleven analyzed metal phases ranges from $\delta^{102 / 99} \mathrm{Ru}$ of $0.02 \%$ to $0.07 \%$ o (average of $\delta^{102 / 99} \mathrm{Ru}_{\text {metal }}=0.04 \pm 0.02 \%$ (95\% conf.), without any clear trends related to the starting material, temperature or capsule material (Table 3). This average is in good agreement with Ru isotopic composition of the starting material of $\delta^{102 / 99} \mathrm{Ru}=0.03 \pm 0.02 \%$ (95 \% conf.; $\left.n=4\right)$. Thus, as predicted from the highly siderophile character of $\mathrm{Ru}$, the metals in our runs are very close to the bulk Ru isotopic composition of the experiments. 
The Ru isotopic signatures in the silicate phases show some fractionation trends depending on the chemical system (Figure 5): The silicate glasses in S-bearing experiments (E088, E089, E097, E098 and E102) have isotopically lighter Ru compositions with $\delta^{102 / 99} \mathrm{Ru}$ values ranging from $-0.01 \pm 0.01 \%$ to $0.07 \pm 0.03 \%$. In contrast, the silicate portions of the two Sn-bearing experiments E110 and E126 have isotopically heavier Ru compositions, with $\delta^{102 / 99} \mathrm{Ru}$ values of $0.22 \pm 0.01 \%$ and $0.21 \pm 0.01 \%$, respectively. The three experiments that contain both $\mathrm{Sn}$ and S show only small or no Ru isotope fractionation, with Ru isotopic compositions of the silicate portions varying between $\delta^{102 / 99} \mathrm{Ru}=-0.01$ $\pm 0.02 \%$ and $0.06 \pm 0.01 \%$. Moreover, the silicate glasses of the experiment without S or Sn (E134) has a Ru isotopic composition of $\delta^{102 / 99} \mathrm{Ru}=0.02 \pm 0.02 \%$ which is very close to the bulk Ru isotopic composition of the metal phases. Similarly, the S-bearing experiments conducted in graphite capsules (E115, E141) show no Ru isotopic fractionation, with silicate glasses having a $\delta^{102 / 99} \mathrm{Ru}$ of 0.03 and 0.05 $\%$, respectively.

\section{Discussion}

\subsection{Ruthenium concentrations in silicate glasses}

Ruthenium concentrations determined by double spike MC-ICPMS are generally 2-4 orders of magnitude larger than those obtained by LA-ICPMS. Whereas the Ru concentrations in the silicate glasses measured with LA-ICPMS are close to the detection limit, MC-ICPMS analyses return concentrations of up to $200 \mu \mathrm{g} / \mathrm{g}$ Ru. Both analytical methods give good and reproducible results for all analyzed reference materials (Methods). Hence, analytical errors, that cause up to three orders of magnitude difference, can be excluded. The high concentrations in the silicate fractions of the experiments determined by MC-ICPMS were first expected to be most likely a result of either external contamination during sample preparation or of insufficient physical separation of silicate glass and Rubearing nuggets or droplets. The latter has been seen previously for Ir, Pt and Re (O'Neill, et al., 1995; Ertel et al., 2008; Medard et al., 2016). Both scenarios were not the case as we show in the following. 


\subsubsection{Testing for metal contamination of the silicate glass}

425

426

427

428

429

430

431

432

433

The possibility of external contamination was evaluated with a metal-free experiment (E125) that was performed and processed in the same way as all former experiments. The Ru concentration measured with LA-ICPMS and quadrupole ICPMS was below the detection limit for both methods and hence excludes any external contamination of the samples during preparation for MC-ICPMS analysis. To exclude contamination by incomplete separation of metal and silicate phase after the experiment (e.g. small metal droplets in the silicate or at the capsule wall), experiment E135 was conducted and analyzed as described above. Ruthenium concentrations in the silicate measured by LA-ICPMS are low $(0.02 \mu \mathrm{g} / \mathrm{g})$ and LA-ICPMS profiles show no gradients across the silicate glass (Figure 3). Analyses of olivine phenocrysts that settled at the bottom of the capsule close to the main metal phase show also no enrichment in Ru (Figure 2). However, the olivine surface (i.e., the olivine-glass interface) as well as analyses at the capsule rim show elevated Ru concentrations of up to $1 \mu \mathrm{g} / \mathrm{g}$, which is about two orders of magnitude higher than the Ru concentrations in the glass (Figure 4a). Optically visible, but i.e. $\mu \mathrm{m}$ sized, metal droplets were clearly too small to be analyzed with LA-ICPMS. We analyzed the droplets together with surrounding material (Laser spot size: 20-60 $\mu \mathrm{m}$ ) and the results show Ru concentrations from 50 to $500 \mu \mathrm{g} / \mathrm{g}$. Further analyses were done on E135 glass in the center of the capsule and on glass of other samples to ascertain that the glass itself is nugget- and droplet-free. Using LA-ICPMS, elevated Ru concentration can be only found at the capsule walls attached to olivines (Figure 1d).

These observations can be best explained by Ru-bearing sulfide nuggets or metal droplets that are attached to the olivine phenocrysts in the ol-rich glass and to the newly formed olivines at the capsule wall. As the metal starting material was placed at the bottom of the capsule in run E135, Ru-bearing nuggets stayed attached only in lower sections of the capsule wall, during melting and during formation of the large metal phase. No Ru-rich nuggets were transported upwards and stuck to capsule wall sections in the top part of the capsule. Olivine itself should normally store small amounts of Ru. Capobianco et al. (1991) and Brenan et al. (2003) find $\mathrm{D}_{\mathrm{RU}}{ }^{\text {olivine-silicate }}$ between 2.2 and 0.2 , depending on 
$\mathrm{fO}_{2}$ and $\mathrm{T}$. However, $\mathrm{D}_{\mathrm{Ru}}{ }^{\text {silicate-sulfide }}$ is very small (c.f. section 4.2) and we can expect similar values for

$450 \quad D_{\mathrm{Ru}}$ olivine-sulfide, which agrees well with the lack of measurable amounts of Ru in olivine.

451 If we assume that the Ru-rich nuggets at the capsule walls are droplets from the primary metal, they 452 should have the same isotopic signature as the main metal phase. In contrast, the measured Ru isotope

453

454

455

456 compositions of the nugget-containing silicate portions are systematically fractionated relative to the metal. Hence, contamination cannot be caused by the observed metal droplets at the capsule wall. Existing metal droplets are part of the primary metal and can neither explain the good reproducibility of the fractionated $\delta^{102 / 99} \mathrm{Ru}$ values (Table 2) nor the lack of correlation between Ru concentration and $\delta^{102 / 99} \mathrm{Ru}$ values (Figure 3). However, this is the case for sulfide nuggets.

\subsubsection{Formation of sulfidic nanonuggets}

The nanonuggets in experiment E176 are attached to the basalt glass-olivine interface and have a diameter of about $\leq 400 \mathrm{~nm}$ (Figure 6). The Ru concentration in the nuggets was too low to be mapped. Quantitative WDS analyses give Ru concentrations of about $435 \pm 120 \mu \mathrm{g} / \mathrm{g}$ which are far above Ru concentrations in the S-doped silicate, but they are not fully reliable on nuggets of this size as all analyses resulted in mixed analyses (Supplementary Table 1). This is caused by contamination of the surrounding basaltic glass and olivine (too large beam excitation volume). Of about 15 analyzed nuggets only two gave totals $\geq 98$ wt.\% and $\leq 102$ wt.\%. Nevertheless, all analyses show strongly increased S concentrations of about 25-35 wt.\% (Supplementary Table 1). Therefore, we assume that the nanonuggets have a sulfidic composition and represent droplets of a third immiscible liquid that formed during the experiment. The generation of larger amounts of sulfide melt in coexistence with metal and silicate phase is shown in experiment E041 (Figure 2). The sulfide layer around the metal phase has 27(1) wt.\% S, 64.0(8) wt.\% Fe and 0.7(2) wt.\% Ru. Assuming similar Ru concentrations in sulfide nuggets, 400 to $7000 \mu \mathrm{g} / \mathrm{g}$ are far above Ru concentration in basalt glass. The formation of these sulfidic nuggets can explain the discrepancy between Ru concentrations determined by LA-ICPMS and MC-ICPMS analyses, as well as the excellent reproducibility of $\delta^{102 / 99} \mathrm{Ru}$ values among S-bearing 
experiments in $\mathrm{MgO}$ capsules. Moreover, the lack of a correlation between Ru concentrations and isotopic compositions shows that MC-ICPMS results are dominated by the sulfide nanonuggets and that significant contributions of initial metal droplets can be excluded.

To add $13 \mu \mathrm{g} / \mathrm{g}$ Ru to the silicate melt bound in sulfide nuggets (with about 500 to $7000 \mu \mathrm{g} / \mathrm{g} \mathrm{Ru}$ ), only a small contribution of sulfide nuggets to the separated silicate fractions is required. For example, based on the masses and Ru concentrations of the silicate sample E098 it can be estimated that a sulfide nugget contribution of $3.2 \mathrm{wt} . \%$ to $0.2 \mathrm{wt} . \%$, respectively, is sufficient to explain the observed high Ru concentrations in the MC-ICPMS analysis.

Sulfide nuggets produced in metal-silicate partition experiments have been already reported by Shahar et al. (2015) who describe "submicrometer sized iron sulfides" within their silicate glass that are in equilibrium with the glass. We assume that the sulfidic nuggets form during melting of the metal phase at the beginning of the experiment. Their attachment to olivines and to the capsule wall argues against late exsolution of Ru-rich nuggets from the melt during quenching. Quench nuggets would be dispersed over a larger range within the glass and would be detectable due to elevated $\mathrm{Ru}$ concentrations by LA-ICPMS (or a better agreement of LA-ICPMS and MC-ICPMS results). Experiment E110 (Figure 1b) shows such exsolution textures after quenching, however the exsolution droplet composition is pure Fe-metal. As the silica melt from which these quench nuggets precipitated can only store very small amounts of Ru, LA-ICPMS analyses of E110 glass and quench metal droplets cannot contain any elevated Ru concentrations $(0.3(1) \mu \mathrm{g} / \mathrm{g})$.

To explain the change in Ru isotope fractionation between S- and Sn-bearing experiments, equivalent Sn-rich nuggets could exist in the Sn-rich, S-free experiments (E110; E126). Fe-rich and Sn-rich phases may coexist at temperatures $>1400^{\circ} \mathrm{C}$ (Franke et al., 2005). Unfortunately, Sn-rich nuggets could not be detected in our experiment with EPMA in "low keV mode". Instead of Sn nuggets, one could also speculate about an alternative scenario: as FeSn alloys have relatively low melting points, larger amounts of Sn could soften the bonding environment in the molten alloy. If Ru would have a bonding 
affinity to $\mathrm{Sn}$ in the alloy, light Ru isotope bonding would be promoted leaving the silicate isotopically

500 heavier. However, this would require the Ru isotope signature to be derived by the silicate and not by

501 Sn-nuggets. In this case, Sn-nuggets are not required and a low Ru concentration would be expected

502 for the bulk silicate analysis with MC-ICPMS, which is not the case for Sn-bearing experiments (e.g.

$503 \quad 198.7 \mu \mathrm{g} / \mathrm{g}$ in E126).

504 This section showed that the analyzed $\Delta^{102 / 99} \mathrm{Ru}$ of most experiments is dominated by either a S- or Sn-

505 rich phase in the silicate glass. The following sections will further discuss the unambiguous nature of

506 the Ru isotopic composition analyzed in the silicate glass, the impact of varying experimental

507 conditions and the mechanisms that might drive these effects.

508

$509 \quad 4.2$ Ruthenium metal-silicate partition coefficients

510 There is scant data on the Ru partitioning between metal and silicate melts or sulfide and silicate melts.

511 Ruthenium element partition coefficients can be calculated in this study from Ru concentrations in the

512 metal and LA-ICPMS analyses of the glasses. For S-bearing experiments log $\mathrm{D}_{\mathrm{Ru}}{ }^{\text {metal-silicate }}$ range from

$5132.0(1)$ to 6.8(3). A $\log \mathrm{D}_{\mathrm{Ru}}{ }^{\text {sulfide-silicate }}$ value of 4.6(2) was calculated for experiment E041. Varying amounts

514 of $\mathrm{S}$ in the metal starting materials (0.001 wt.\%; $0.01 \mathrm{wt} . \% ; 0.1 \mathrm{wt} . \%$ ) show that $\log \mathrm{D}_{\mathrm{Ru}}{ }^{\text {metal-silicate }}$

515 decreases with increasing amount of $S$ in the system (Figure 7). This in good agreement with

516 experimental studies from Laurenz et al. (2016). They show that Ru and other HSEs become less

517 siderophile with increasing $S$ concentration in the silicate melt. The calculated log $\mathrm{D}_{\mathrm{Ru}}{ }^{\text {metal-silicate }}$ and $\log$

$518 \mathrm{D}_{\mathrm{Ru}}{ }^{\text {sulfide-silicate }}$ from Laurenz et al. (2016) are slightly lower when compared to values from this study

519 (Figure 7). The different partition coefficients may be explained by different pressures or

520 temperatures, as Laurenz et al. (2016) reported that $\log \mathrm{D}_{\mathrm{Ru}}{ }^{\text {metal-silicate }}$ decrease with increasing pressure

521 and our runs were performed at $1 \mathrm{GPa}$, whilst experiments from Laurenz et al. (2016) were conducted

522 at $11 \mathrm{GPa}$ (Figure 7). 


\subsection{Ruthenium isotope fractionation}

Mass-dependent $\mathrm{Ru}$ isotope fractionation between quenched metal melt and the nugget-bearing silicate glasses is small but detectable (Figure 5). Sulfur-bearing experiments in MgO capsules show an average $\mathrm{Ru}$ isotope fractionation factor $\Delta^{102 / 99} \mathrm{Ru}$ metal-sulfide of $0.11 \pm 0.03 \%$ (95\% conf.) where $\Delta^{102 / 99} \mathrm{Ru}$ metal-sulfide $=\delta^{102 / 99} \mathrm{Ru}$ metal $-\delta^{102 / 99} \mathrm{Ru}$ sulfide. The two $\mathrm{Sn}$-bearing experiments in MgO capsules show $\Delta^{102 / 99} \mathrm{Ru}$ metal-Sn-phase values of $-0.18 \%$ $\pm 0.01 \%$. These differences in the direction of the isotope fractionation can be best explained with the sulfidic or and Sn-rich phase, respectively, that dominate the isotopic signature. The very small isotope fractionation in the S- and Sn-free experiments in a MgO capsule (E134; Table 3) shows that in the S- or Sn-bearing experiments the measured Ru isotope fractionation is controlled by formation of S- or Sn-bearing phases, respectively. The S+Sn-bearing experiments show an average $\mathrm{Ru}$ isotope fractionation factor $\Delta^{102 / 99} \mathrm{Ru}_{\text {metal-sulfide }}$ of $-0.02 \pm 0.02 \%$ o (Figure 5). These runs were originally conducted to lower the melting temperature and allow experiments at $1300{ }^{\circ} \mathrm{C}$. Given these low fractionation factors, it could be assumed that sulfide nanonuggets and a Sn-phase exists in the silicate glass. The two effects of S- and Sn bearing phases would counterbalance each other in experiment E104, E109 and E128 and we would expect a correlation between S- and Sn-content in the silicate phase. However, both elements were not measured with MC-ICPMS and the samples could not be analyzed by EPMA. The Ru concentration in the silicate glass is also not higher $(22-96 \mu \mathrm{g} / \mathrm{g})$ than in experiments with only $\mathrm{S}$ or $\mathrm{Sn}$ in the starting material.

In graphite capsules olivine cannot form at the capsule walls and hence the formation of S-rich nuggets is prohibited. Thus, the Ru concentration in the silicate fractions of the graphite experiments are low (7-8 ppm, measured with MC-ICPMS) and reproducible. Nevertheless, these concentrations are higher than results from LA-ICPMS measurements and the formation of S-rich nuggets, like in MgO-capsule experiments, can be excluded due to the lack of any Ru isotope fractionation in graphite experiments. The slightly higher Ru concentration in silicates from graphite capsule experiments can be best explained by contamination with primary metal droplets. 
For experiments at $1600{ }^{\circ} \mathrm{C} \mathrm{Hin} \mathrm{et} \mathrm{al.} \mathrm{(2013)} \mathrm{found} \mathrm{that} \mathrm{isotope} \mathrm{fractionation} \mathrm{starts} \mathrm{to} \mathrm{be} \mathrm{dominated}$

by kinetic fractionation in $\mathrm{MgO}$ capsules as the element of interest (Mo in their study) fractionates

from the metal phase into a silicate whose composition changes over time. Therefore, Hin and coworkers treated these experiments separately. At $1600{ }^{\circ} \mathrm{C}$ the $\mathrm{MgO}$ capsule dissolves much faster and Hin et al. (2013) see an increase of Mo element concentration, as well as a change of isotope fractionation over time. Ruthenium experiments at $1600^{\circ} \mathrm{C}$ in $\mathrm{MgO}$ capsules from this study also show significant increase of $\mathrm{MgO}$ in the melt, extensive olivine growth (Figure 2), and metal exsolution within the silicate melt. However, LA-ICPMS data from E098 and E102 show no elevated Ru concentrations. They show comparable isotope fractionation to experiments conducted at temperatures $<1600{ }^{\circ} \mathrm{C}$. Thus, the change in silicate melt composition does not affect the Ru concentration in the silicate melt.

\subsection{Ruthenium bonding environment and its influence on isotope fractionation}

Our experiments are not designed to study Ru element coordination in the melt or its valence state in the different phases. Discrete data are lacking but element bonding is crucial for isotope fractionation and will be discussed shortly.

Ru has a higher valence state in the silicate melt than in the metal melt. While the Ru oxidation state in the metal is 0 , Ru can be $+\mathrm{II},+\mathrm{III},+\mathrm{IV},+\mathrm{VI}$ or $+\mathrm{VIII}$ when bonded to non-metals. Laurenz et al. (2013) propose $\mathrm{Ru}^{4+}$ to be the dominant cationic species for their experiments in picritic melts. In their experiments, $\mathrm{Ru}$ bonds either with $\mathrm{O}^{2-}$ or $\mathrm{S}^{2-}$, albeit the bonding with $\mathrm{S}^{2-}$ is about 900 times stronger due to the chalcophile character of Ru (Laurenz et al., 2013). For RuS 2 in sulfide nanonuggets, the valence state of Ru would vary between metal and sulfide from 0 to +IV as it is supposed to be for metal and silicate. Ru isotope fractionation should be dominated by the varying bonding length of RuFe, Ru-O and Ru-S. Schauble (2004) shows that higher valence states and lower coordination states are generally associated with stiffer bonds. These stiff bonds are favored by the heavier isotope of the element of interest (Bigeleisen, 1965). However, this does not seem to be the case for the sulfide nanonuggets, and the isotope fractionation observed in our S-bearing experiments in $\mathrm{MgO}$ capsules. 
affinity of lighter Ru isotopes for the sulfide nuggets relative to the metal phase. This is contrary to expectations from theory (Bigeleisen, 1965; Schauble, 2004) and cannot be simply explained by a lower valence state than +IV. The isotopic fractionation of other elements such as Fe in S-bearing systems is also not well constrained. Several studies (Williams et al., 2006; Schuessler et al., 2007; Polyakov and Soultanov, 2011) show that Fe sulfides are depleted in heavy Fe isotopes relative to their silicates. In contrast, Shahar et al. (2015) find good correlations between increasing sulfur content in the metal and higher $\Delta^{57} \mathrm{Fe}_{\text {metal-silicate }}$ values, which they conclude is caused by different bonding structures of sulfides and S-rich metal alloys. Their results show that the heavier Fe isotopes have a stronger affinity to bond with $\mathrm{S}$ in sulfides but not with $\mathrm{S}$ in metal. Hence, one could also speculate that other factors like coordination of Ru or Fe within the melts have a stronger effect on isotope fractionation than their valence state.

For the Sn-bearing experiments of this study, it can be concluded that the negative $\Delta^{102 / 99} \mathrm{Ru}$ values are derived from coordination differences and a Ru-Sn bonding that varies from the sulfide phase, as well as from the Fe dominated metal phase. However, Sn can theoretically have valence states between IV and +IV but not much is known about Ru bonding in such phases. The effect of $\mathrm{Sn}$ on metal isotope fractionation in experiments has been addressed in a few studies. Shahar et al. (2015) and Young et al. (2015) propose that large amounts of Sn in the metal melt changes the bonding environment and should therefore influence isotope fractionation of elements such as Fe or Mo. Nevertheless, Hin et al. (2013) conducted experiments on Mo isotope fractionation between Sn-free and Sn-bearing metal and silicate melts, and could not find any significant differences. In our experiments, there is a significant effect of Sn (in the metal phase) on Ru isotope fractionation (c.f. also Hin et al. 2012; 2014). But to better understand Ru isotope fractionation between liquid metal, sulfide and silicate, further work is required on Ru valence state, bonding environment, and coordination in these phases.

\subsection{Implications for Ru isotope fractionation in natural Fe-FeS systems}

There is no clear temperature dependency in Figure 5 for metal-sulfide fractionation experiments between $1400{ }^{\circ} \mathrm{C}$ and $1600{ }^{\circ} \mathrm{C}$ as their variation is too small. To better describe the change of $\mathrm{Ru}$ 
601 isotope fractionation with varying temperature a best-fit approach can be applied: Bigeleisen and 602 Mayer (1947) and Urey (1947) show that equilibrium mass dependent isotope fractionation is 603 proportional to $A / T^{2}$, where $A$ is a constant that can be either determined from experiments or 604 theoretically (e.g. Bourdon et al., 2018). This results in a decreasing magnitude of isotope fractionation 605 with increasing temperature. To extrapolate the effect of temperature on Ru isotope fractionation, 606 one can use a Least Square Approach for $A / T^{2}$ as it is shown in Figure 8. For this fit a value of $0.24( \pm$ $6070.03) \times 10^{6}$ was calculated for $A$ on the base of the S-bearing experiments at $1400^{\circ} \mathrm{C}, 1500^{\circ} \mathrm{C}$ and 1600 $608{ }^{\circ} \mathrm{C}$ (E088, E089, E097, E098, E102; Table 3). Thus, the temperature dependence of the Ru isotope 609 fractionation between metal and sulfide can be described as:

$\Delta^{102 / 99} R u_{\text {metal-sulfide }}=\frac{0.24( \pm 0.03) * 10^{6}}{T^{2}}$

611 The fractionation of $\Delta^{102 / 99} \mathrm{Ru}$ metal-sulfide is not resolvable $\left(<0.04 \%\right.$ ) at temperatures above $2500{ }^{\circ} \mathrm{C}$ 612 (Figure $8 \mathrm{~b}$ ) and $\Delta^{102 / 99} \mathrm{Ru}$ metal-silicate is already negligible at $>1600{ }^{\circ} \mathrm{C}$. Given these results from Figure 8 613 and the even smaller silicate-metal fractionation $\left(0.02 \pm 0.02 \%\right.$ at $\left.1600{ }^{\circ} \mathrm{C}\right)$, significant $\mathrm{Ru}$ isotope 614 fractionation during Earth's core formation $\left(T>3500{ }^{\circ} \mathrm{C}\right)$ is not expected. These finding are in good 615 agreement with the results from Hopp and Kleine (2018) who did not see any distinguishable Ru 616 isotope fractionation between chondritic meteorites and terrestrial peridotites.

617 It has been recently shown that the partitioning behavior of some HSEs may be different under Earth's 618 core formation conditions and that they will not be quantitatively removed from the mantle by metal619 silicate partitioning but would be overabundant and display non-chondritic relative abundances 620 (Righter et al., 2008; Rubie et al., 2016; Righter et al., 2018). Therefore, the relative chondritic 621 abundances of HSEs in Earth's mantle require an additional removal of HSEs by a sulfide matte during 622 the late stages of core formation before a chondritic late veneer is added (O'Neil, 1991; Rubie et al., 623 2016; Righter et al., 2018). This Hadean matte model proposes that the exsolution of FeS from the 624 magma ocean during cooling affects HSE/Ir ratios in the Earth's mantle, as they show different behavior 625 (Laurenz et al., 2016; Rubie et al., 2016). However, high temperatures above $2000{ }^{\circ} \mathrm{C}$ (rather even 3000 
627 for metal-silicate and metal-sulfide fractionation, significant sulfide-silicate Ru isotope fractionation is 628 also not expected at these temperatures.

629 The observed metal-sulfide isotope fractionation of $\mathrm{Ru}$ stable isotopes could be important to 630 understand planetary processes occurring at lower temperatures that are closer to the temperatures 631 from our experiments: Hopp et al. (2018) determined mass-dependent Ru isotope signatures of 632 various magmatic iron meteorites. These meteorites stem from the metallic cores of differentiated 633 protoplanetary bodies. The magmatic iron displays heavy and variable $\delta^{102 / 99} \mathrm{Ru}$ compared to 634 undifferentiated material such as ordinary chondrites. The $\delta^{102 / 99} \mathrm{Ru}$ values vary between $-0.07 \pm 0.05$ 635 and $0.85 \pm 0.05$ and show a correlation of increasingly heavier Ru isotopic composition with decreasing 636 Ru contents. Hopp et al. (2018) interpret these findings with progressive fractional crystallization of 637 the metallic liquid, which leads to enrichment in FeS and heavier Ru isotope signatures in the remaining 638 melt (Hopp et al., 2018). These results suggest that fractionation of Ru was controlled by the increasing 639 amount of sulfur in the melt which might cause $\mathrm{Ru}$ isotope fractionation between $\mathrm{Fe}$ and $\mathrm{FeS}$ 640 dominated phases. This fractionation model requires that the remaining S-rich melt is isotopically 641 heavier than the solidifying metal, which is contrary to results from this study. However, the phases 642 involved during the crystallization of magmatic iron meteorites are S-poor solid metal and S-rich 643 metallic metal that are distinct to the S-rich metal and sulfide nuggets that control the Ru isotopic 644 fractionation in our experiments. Furthermore, the incongruent crystallization itself might play a role 645 in the Ru isotope fractionation of magmatic iron meteorites but is not represented in the experiments. 646 Hence, the experimental results on the Ru isotope fractionation do not represent the mechanisms that 647 control Ru isotope fractionation during fractional crystallization of asteroidal cores.

648 Primtive achondrites are meteorites that derive from partially differentiated parent bodies (e.g., 649 Weisberg et al., 2006). Thus, while magmatic iron meteorites are expected to have already experienced 650 core formation and core mantle segregation on their parent body, primitive achondrites represent 651 earlier stages of differentiation. These meteorites experienced only partial silicate melting and 
incomplete metal segregation (e.g. Keil, 2014; Keil and McCoy, 2017). Nevertheless, they provide evidence for variable extraction of S-rich and S-poor Fe-Ni-S melts (Day et al., 2012; Goodrich et al., 2013; Dhaliwal et al., 2017; Day et al., 2019). Hopp and Kleine (2021) reported that primitive achondrites from different groups, i.e. brachinites, acapulcoite-lodranites, and ureilites, have heavier $\delta^{102 / 99} \mathrm{Ru}$ values relative to chondrites. The extraction of S-rich Fe-Ni-S melts cannot easily explain the observed $\mathrm{Ru}$ isotopic fractionation with reasonable degrees of melt extraction. However, the extraction of S-poor metallic melts at higher temperatures can produce the heavier $\delta^{102 / 99} \mathrm{Ru}$ values of primitive achondrites with realistic degrees of melt extraction (Hopp and Kleine, 2021). Thus, the results from the S-rich experiments reported here are likely not directly applicable to the main driver of isotopic fractionation in primitive achondrites, i.e. extraction of S-poor metallic melts. However, they might represent initial extraction of S-rich Fe-Ni-S during partial differentiation of planetesimals that contributed to the bulk isotopic composition. Interestingly, the observed Ru isotope fractionation in primitive achondrites agrees with the magnitude and direction of the isotope fractionation observed in this study.

\section{Conclusions}

Our experiments were designed to study mass-dependent isotope fractionation of stable Ru isotopes between metal melt and silicate melt. This metal-silicate fractionation turned out to be too small and negligible for core formation temperatures. However, in several experiments significant Ru isotope fractionation was caused by metal-sulfide fractionation with a lighter Ru isotope composition in the sulfide phase. The addition of small amounts of S (used as a flux) to the experimental system led to the formation of Ru-bearing sulfide nuggets which dominated the measurements. This effect could only seen in $\mathrm{MgO}$ capsules but not in graphite capsules. The direction of this fractionation contradicts what would have been expected by theoretical approaches from literature: a heavier isotopic composition for Ru in a non-metallic valence state. Moreover, the addition of $\mathrm{Sn}$ instead of $\mathrm{S}$ to the starting material results very likely in a Sn-rich phase that has a heavier Ru isotope composition than the Fe-metal. In 
consequence, the exchange of small amounts of S with Sn (or vice-versa) in the starting material can flip over the direction of Ru isotope fractionation in the experimental system. There are scant data about the coordination and the real valence state of $\mathrm{Ru}$ in sulfides or other compounds. To better understand the effect of the chemical composition on Ru (or HSE in general) isotope fractionation, we need to better understand their bonding in the studied phases.

The magnitude of $\mathrm{Ru}$ isotope fractionation is small in our experiments. Since equilibrium isotope fractionation decreases with increasing temperature, we do not expect any resolvable isotope fractionation during core formation temperatures $\left(>2000^{\circ} \mathrm{C}\right)$ or a late sulfide segregation from a magma ocean.

\section{Acknowledgements}

Our thanks go to the excellent workshops of the Inst. for Mineralogy in Münster, especially Maik Trogisch and Michael Feldhaus for their help with capsule preparation and sample mounting, and Beate Schmitte for help with microprobe analyses and LA-ICP-MS. We are grateful to Marian Horstmann, Thorsten Kleine and Remco Hin for constructive comments that helped to improve the paper. Finally, we want to thank Mathieu Roskosz, an anonymous reviewer, and the editor for their supportive comments, criticism and questions which helped again to improve the paper significantly.

This work was supported by the Deutsche Forschungsgemeinschaft (DFG) within the Collaborative Research Centre SFB-TRR 170 (subproject B2). This is TRR 170 Publication no. xx.

\section{References}

Becker H., Horan M. F., Walker R. J., Gao S., Lorand J. P. and Rudnick R. L. (2006) Highly siderophile element composition of the Earth's primitive upper mantle: constraints from new data on peridotite massifs and xenoliths. Geochim. Cosmochim. Acta 70, 4528-4550.

Bigeleisen J. (1965) Chemistry of Isotopes: Isotope chemistry has opened new areas of chemical physics, geochemistry, and molecular biology. Science 147, 463-471. 
702

703

704

705

706

707

708

709

710

711

712

713

714

715

716

717

718

719

720

721

722

723

724

Bigeleisen J. and Mayer M. G. (1947) Calculation of equilibrium constants for isotopic exchange reactions. J. Chem. Phys. 15, 261-267.

Borisov A. and Palme H. (2000) Solubilities of noble metals in Fe-containing silicate melts as derived from experiments in Fe-free systems. Am. Mineral. 85, 1665-1673.

Bourdon B., Roskosz M. and Hin R. C. (2018) Isotope tracers of core formation. Earth Sci. Rev. 181, $61-81$.

Brenan J.M., McDonough W.F., Dalpé C. (2003) Experimental constraints on the partitioning of rhenium and some platinum-group elements between olivine and silicate melt Earth Planet. Sci. Lett. 212, 135-150.

Capobianco C.J., Drake, M.J., Rogers, P.S.Z. (1991) Partitioning of Ru, Rh and Pd. Abstract of the Lunar and Planetary Science Conference 22, p. 179.

Day J.M.D., Walker R. J., Ash R. D., Liu Y., Rumble D., Irving A. J., Goodrich C. A., Tait K., McDonough W. F. and Taylor L. A. (2012) Origin of felsic achondrites Graves Nunataks 06128 and 06129, and ultramafic brachinites and brachinite-like achondrites by partial melting of volatile-rich primitive parent bodies. Geochim. Cosmochim. Acta 81, 94-128.

Day J.M.D., Walker R.J., Warren J.M. (2017). ${ }^{186} \mathrm{Os}-{ }^{187}$ Os and highly siderophile element abundance systematics of the mantle revealed by abyssal peridotites and Os-rich alloys. Geochim. Cosmochim. Acta 200, 232-254.

Day J. M. D., Corder C. A., Assayag N. and Cartigny P. (2019). Ferrous oxide-rich asteroid achondrites. Geochim. Cosmochim. Acta 266, 544-567.

Dhaliwal J. K., Day J. M. D., Corder C. A., Tait K. T., Marti K., Assayag N., Cartigny P., Rumble D. and Taylor L.A. (2017) Early metal-silicate differentiation during planetesimal formation revealed by acapulcoite and lodranite meteorites. Geochim. Cosmochim. Acta 216, 115-140. 
Drouin D., Couture A. R., Joly D., Tastet X., Aimez V. and Gauvin R. (2007). CASINO V2. 42-a fast and easy-to-use modeling tool for scanning electron microscopy and microanalysis users. Scanning 29(3), 92-101.

Ertel W., Dingwell D. B. and Sylvester P. J. (2008) Siderophile elements in silicate melts - A review of the mechanically assisted equilibration technique and the nanonugget issue. Chem. Geol. 248, 119-139.

Fischer-Gödde M. and Becker H. (2012) Osmium isotope and highly siderophile element constraints on ages and nature of meteoritic components in ancient lunar impact rocks. Geochim. Cosmochim. Acta 77, 135-156.

Fortenfant S. S., Gunther D., Dingwell D. B. and Rubie D. C. (2003) Temperature dependence of Pt and Rh solubilities in a haplobasaltic melt. Geochim. Cosmochim. Acta 70, 742-756.

Franke P., Neuschütz D. and Scientific Group Thermodata Europe (SGTE) (2005) Fe-Sn. In Binary systems. Part 3: Binary Systems from Cs-K to Mg-Zr (eds. P. Franke and D. Neuschütz). Springer Berlin Heidelberg. Berlin, Heidelberg.

Goodrich C. A., Ash R. D., Orman J. A. V., Domanik K. and McDonough W. F. (2013) Metallic phases and siderophile elements in main group ureilites: Implications for ureilite petrogenesis. Geochim. Cosmochim. Acta 112, 340-373.

Gervasoni F., Klemme S., Rohrbach A., Grützner T., Berndt J. (2017) Experimental constraints on mantle metasomatism cause by silicate and carbonate melts. Lithos 282-283, 173-186.

Grützner T., Kohn S. C., Bromiley D.W., Rohrbach A., Berndt J., Klemme S. (2017) The storage capacity of fluorine in olivine and pyroxene under upper mantle conditions. Geochim. Cosmochim. Acta 208, 160-170. 
Hin R. C., Schmidt M. W. and Bourdon B. (2012) Experimental evidence for the absence of iron isotope fractionation between metal and silicate liquids at $1 \mathrm{GPa}$ and $1250-1300^{\circ} \mathrm{C}$ and its cosmochemical consequences. Geochim. Cosmochim. Acta 93, 164-181.

Hin R. C., Burkhardt C., Schmidt M. W., Bourdon B. and Kleine T. (2013) Experimental evidence for Mo isotope fractionation between metal and silicate liquids. Earth Planet. Sci. Lett. 379, 38-48.

Hin R. C., Fitoussi C., Schmidt M. W. and Bourdon B. (2014) Experimental determination of the Si isotope fractionation factor between liquid metal and liquid silicate. Earth Planet. Sci. Lett. 387, $55-66$.

Holzheid A., Palme H. and Chakraborty S. (1997) The activities of $\mathrm{NiO}, \mathrm{CoO}$ and $\mathrm{FeO}$ in silicate melts. Chem. Geol. 139, 21-38.

Holzheid A., Sylvester P., O'Neill H. S. C., Rubie D. C. and Palme H. (2000) Evidence for a late chondritic veneer in the Earth's mantle from high-pressure partitioning of palladium and platinum. Nature 406, 396-399.

Hopp T. and Kleine T. (2021) Ruthenium isotopic fractionation in primitive achondrites: Clues to the early stages of planetesimal melting. Geochim. Cosmochim. Acta, in press.

Hopp T. and Kleine T. (2018) Nature of late accretion to Earth inferred from mass-dependent Ru isotopic compositions of chondrites and mantle peridotites. Earth Planet. Sci. Lett. 494, 50-59.

Hopp T., Fischer-Gödde M. and Kleine T. (2016) Ruthenium stable isotope measurements by double spike MC-ICPMS. J. Anal. At. Spectrom. 31, 1515-1526.

Hopp T., Fischer-Gödde M. and Kleine T. (2018) Ruthenium isotope fractionation in protoplanetary cores. Geochim. Cosmochim. Acta 223, 75-89.

Keil K. (2014) Brachinite meteorites: Partial melt residues from an FeO-rich asteroid. Geochemistry 74, 311-329.

Keil K. and McCoy T. J. (2018) Acapulcoite-lodranite meteorites. Geochemistry 78, 153-203. 
771

772

773

774

775

776

777

778

779

780

781

782

783

784

785

786

787

788

789

790

791

792

793

794

Kimura K. L. R. and Anders E. (1974) Distribution of gold and rhenium between nickel-iron and silicate melts: implications for the abundance of siderophile elements on the Earth and Moon. Geochim. Cosmochim. Acta 38, 683-701.

Klemme S., O'Neill H. St. C. (1997). The reaction $\mathrm{MgCr}_{2} \mathrm{O}_{4}+\mathrm{SiO}_{2}=\mathrm{Cr}_{2} \mathrm{O}_{3}+\mathrm{MgSiO}$ and the free energy of formation of magnesiochromite $\left(\mathrm{MgCr}_{2} \mathrm{O}_{4}\right)$. Contrib. Mineral. Petrol, 130, 59-65.

Kyser T. K., Lesher C. E. and Walker D. (1998) The effects of liquid immiscibility and thermal diffusion on oxygen isotopes in silicate liquids. Contrib. Mineral. Petrol. 133, 272-281.

Laurenz V., Fonseca R. O., Ballhaus C., Jochum K. P., Heuser A. and Sylvester P. J. (2013) The solubility of palladium and ruthenium in picritic melts: 2 . The effect of sulfur. Geochim. Cosmochim. Acta $108,172-183$.

Laurenz V., Rubie D. C., Frost D. J. and Vogel A. K. (2016) The importance of sulfur for the behavior of highly-siderophile elements during Earth's differentiation. Geochim. Cosmochim. Acta 194, 123138.

Ma Z. (2001) Thermodynamic description for concentrated metallic solutions using interaction parameters. Metall. Mater. Trans. B 32, 87-103.

Mann U., Frost D. J., Rubie D. C., Becker H. and Audétat A. (2012) Partitioning of Ru, Rh, Pd, Re, Ir and Pt between liquid metal and silicate at high pressures and high temperatures - Implications for the origin of highly siderophile element concentrations in the Earth's mantle. Geochim. Cosmochim. Acta 84, 593-613.

Médard E., Martin, A. M., Righter, K., Lanziroti, A., Newville M., (2016) Platinum partitioning at low oxygen fugacity: Implications for core formation processes. Abstract of the Lunar and Planetary Science Conference, LPI Contribution No. 1903, p.2801.

Moynier F., Yin Q. Z. and Schauble E. A. (2011) Isotopic evidence of Cr partitioning into Earth's core. Science 331, 1417-1420. 
O'Neill H. St.C.(1991) The origin of the Moon and the early history of the Earth - A chemical model Part 2: The Earth. Geochim. Cosmochim. Acta 43, 1159-1172.

O’Neill H. St.C., Dingwell D. B., Borisov A., Spettel B. and Palme H. (1995) Experimental petrochemistry of some highly siderophile elements at high temperatures, and some implications for core formation and the mantle's early history. Chem. Geol. 120, 255-273.

Poitrasson F., Roskosz M., Corgne A. (2009) No iron isotope fractionation between molten alloys and silicate melt to $2000^{\circ} \mathrm{C}$ and $7.7 \mathrm{GPa}$. Experimental evidence and implications for planetary differentiation and accretion. Earth Planet. Sci. Lett. 278 (3-4), S. 376-385

Polyakov V. B. and Soultanov D. M. (2011) New data on equilibrium iron isotope fractionation among sulfides: Constraints on mechanisms of sulfide formation in hydrothermal and igneous systems. Geochim. Cosmochim. Acta 75, 1957-1974.

Richter F. M., Watson E., Mendybaev R. A., Teng F.-Z. and Janney P. E. (2008) Magnesium isotope fractionation in silicate melts by chemical and thermal diffusion. Geochim. Cosmochim. Acta 72, $206-220$.

Righter K., Humayun M. and Danielson L. (2008) Partitioning of palladium at high pressures and temperatures during core formation. Nat. Geosci. 1, 321-323.

Righter K., Pando K., Humayun M., Waeselmann N., Yang S., Boujibar A., Danielson, L.R. (2018) Effect of silicon on activity coefficients of siderophile elements ( $\mathrm{Au}, \mathrm{Pd}, \mathrm{Pt}, \mathrm{P}, \mathrm{Ga}, \mathrm{Cu}, \mathrm{Zn}$, and $\mathrm{Pb}$ ) in liquid Fe: Roles of core formation, late sulfide matte, and late veneer in shaping terrestrial mantle geochemistry. Geochim. Cosmochim. Acta 232, 101-123.

Roskosz M., Luais B., Watson H. C., Toplis M. J., Alexander C. and Mysen B. O. (2006) Experimental quantification of the fractionation of Fe isotopes during metal segregation from a silicate melt. Earth Planet. Sci. Lett. 248, 851-867. 
Roskosz M., Caracas R. and Rouxel O. (2009) Advances in experimental and theoretical isotope geochemistry. Chem. Geol. 267, 109-110.

Rubie D. C., Laurenz V., Jacobson S. A., Morbidelli A., Palme H., Vogel A. K. and Frost D. J. (2016) Highly siderophile elements were stripped from Earth's mantle by iron sulfide segregation. Science 353, 1141-1144.

Rudge J. F., Reynolds B. C. and Bourdon B. (2009) The double spike toolbox. Chem. Geol. 265, 420431.

Savage P. S., Moynier F., Chen H., Shofner G., Siebert J., Badro J., Puchtel I. S. (2015) Copper isotope evidence for large-scale sulphide fractionation during Earth's differentiation. Geochem. Persp. Let. I, 53-64.

Schauble E. A. (2004) Applying stable isotope fractionation theory to new systems. In Reviews in mineralogy and geochemistry - Geochemistry of non-traditional stable isotopes (eds. C. M. Johnson, B. L. Beard and F. Albarêde). Mineralogical Society of America. Washington, DC, pp. 65111.

Schuessler J. A., Schoenberg R., Behrens H. and Blanckenburg F. v. (2007) The experimental calibration of the iron isotope fractionation factor between pyrrhotite and peralkaline rhyolitic melt. Geochim. Cosmochim. Acta 71, 417-433.

Scott E. R. D. (1972) Chemical fractionation in iron meteorites. Geochim. Cosmochim. Acta 36, 12051236.

Scott E. R. D. and Wasson T. (1975) Classification and properties of iron meteorites. Rev. Geophys. Space Phy. 13, 527-545.

Shahar A., Hillgren V. J., Young E. D., Fei Y. W., Macris C. A. and Deng L. W. (2011) High temperature Si isotope fractionation between iron metal and silicate. Geochim. Cosmochim. Acta 75, 76887697. 
842 Shahar A., Hillgren V. J., Horan M. F., Mesa-Garcia J., Kaufman L. A. and Mock T. D. (2015) Sulfur-

843 controlled iron isotope fractionation experiments of core formation in planetary bodies. Geochim.

844 Cosmochim. Acta 150, 253-264.

845 Shirey S. B. and Walker R. J. (1995) Carius tube digestion for low-blank rhenium-osmium analysis.

$846 \quad$ Anal. Chem. 67, 2136-2141.

847 Siebert C., Nägler T. F. and Kramers J. D. (2001) Determination of molybdenum isotope fractionation

848 by double-spike multicollector inductively coupled plasma mass spectrometry. Geochem.

$849 \quad$ Geophys. Geosyst. 2 (7).

850 The Japan Society for the Promotion of Science, the 19th Committee on Steelmaking (1988)

851 Steelmaking Data Sourcebook, Part 2: Recommended Values of Activity and Activity Coefficients,

852 and Interaction Parameters of Elements in Iron Alloys. Gordon and Breach Science Publishers,

$853 \quad$ Montreux.

854 Urey H. C. (1947) The thermodynamic properties of isotopic substances. J. Chem. Soc. 0, 562-581.

855 Wade J. and Wood B. J. (2005) Core formation and the oxidation state of the Earth. Earth Planet. Sci.

$856 \quad$ Lett. 236, 78-95.

857 Walker R. J., Bermingham K., Liu J., Puchtel I. S., Touboul M. and Worsham E. A. (2015) In search of

858 late-stage planetary building blocks. Chem. Geol. 411, 125-142.

859 Wänke H. (1981) Constitution of terrestrial planets. Philos. T. R. Soc. A 303, 287-302.

860 Weisberg M. K., McCoy, T. J, Krot, A. N. (2006) Systematics and evaluation of meteorite

861 classification. Meteorites and the Early Solar System II, University of Arizona Pres, 19-52.

862 Williams H. M., Markowski A., Quitté G., Halliday A. N., Teutsch N. and Levasseur S. (2006) Fe isotope

863 fractionation in iron meteorites: New insights into metal-sulphide segregation and planetary

864 accretion. Earth Planet. Sci. Lett. 250, 486-500. 
865 Young E. D., Manning C. E., Schauble E. A., Shahar A., Macris C. A., Lazar C. and Jordan M. (2015)

866 High-temperature equilibrium isotope fractionation of non-traditional stable isotopes. Chem.

867 Geol. 395, 176-195.

868

869 


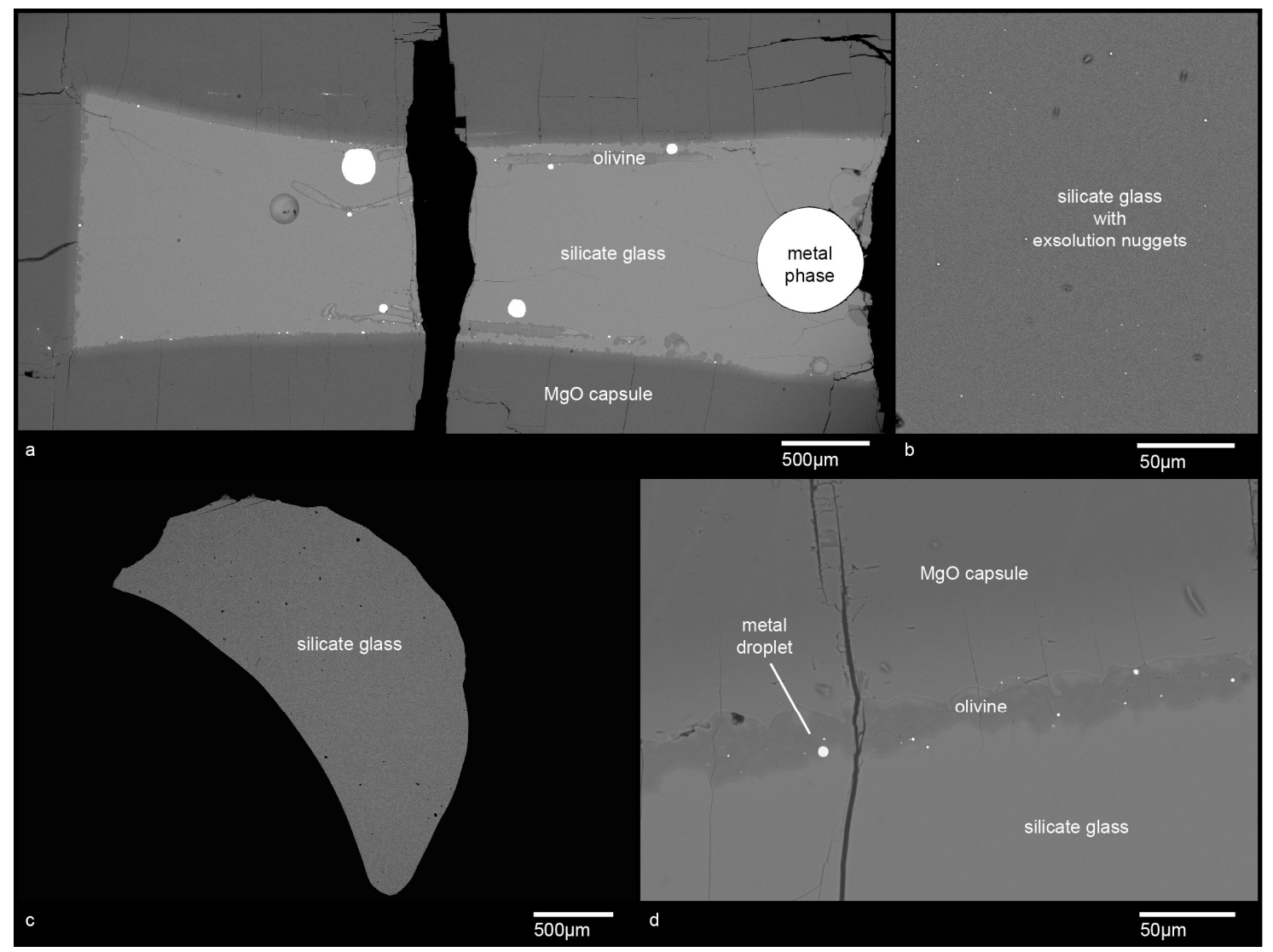

872 Figure 1: Back-scattered electron (BSE) image of experiments a) E017, b), c) E110 and d) E041. a) A

873 homogeneous mixture of metal and silicates in the starting materials results in numerous medium

874 size metal blobs in the run product. b) and c) nano size nuggets (bright spots) in the silicate glass are

875 found in several experiments but show these nuggets results in no elevation in Ru concentrations, and

876 hence these nuggets are interpreted to be formed by Fe-exsolution during the quench of the run. $d)$

877 metal droplets that form during the run and that are attached to the olivine layer at the capsule wall. 


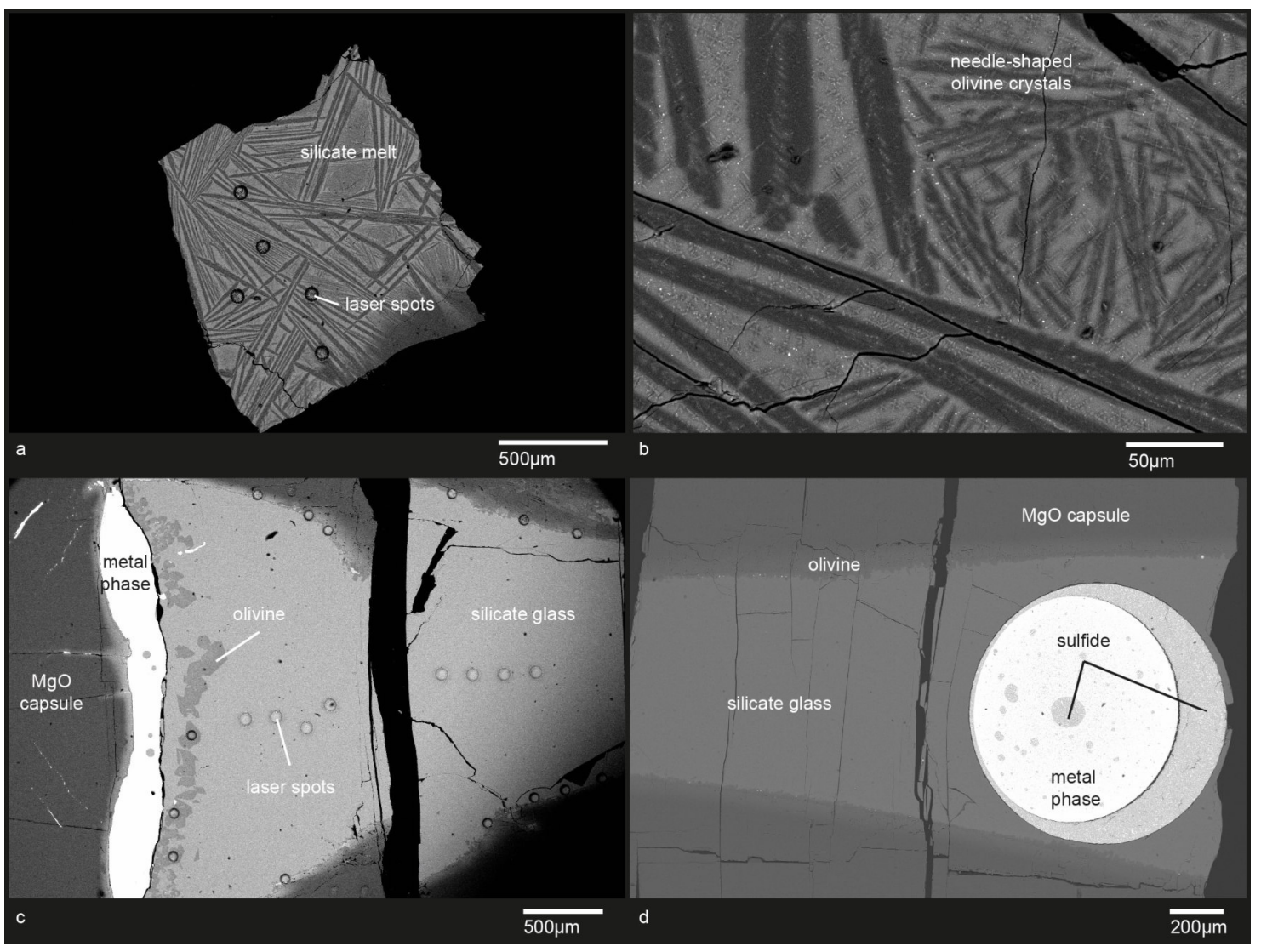

880 Figure 2: Back-scattered electron (BSE) image of experiments a) E134, b) E102, c) E135 and d) E041.

881 a), b) Needle-shaped olivine textures in experiments at $1600{ }^{\circ} \mathrm{C}$ are caused by fast dissolution of $\mathrm{MgO}$

882 in the basaltic melt. c) nano size nuggets (bright spots) are found in the silicate glass of several

883 experiments but show no elevation in Ru concentration and hence these nuggets are interpreted to be

884 formed by Fe-exsolution during the quench of the run. d) In runs with high amount of $S$ in the starting

885 material, a sulfide layer forms around the metal phase. 

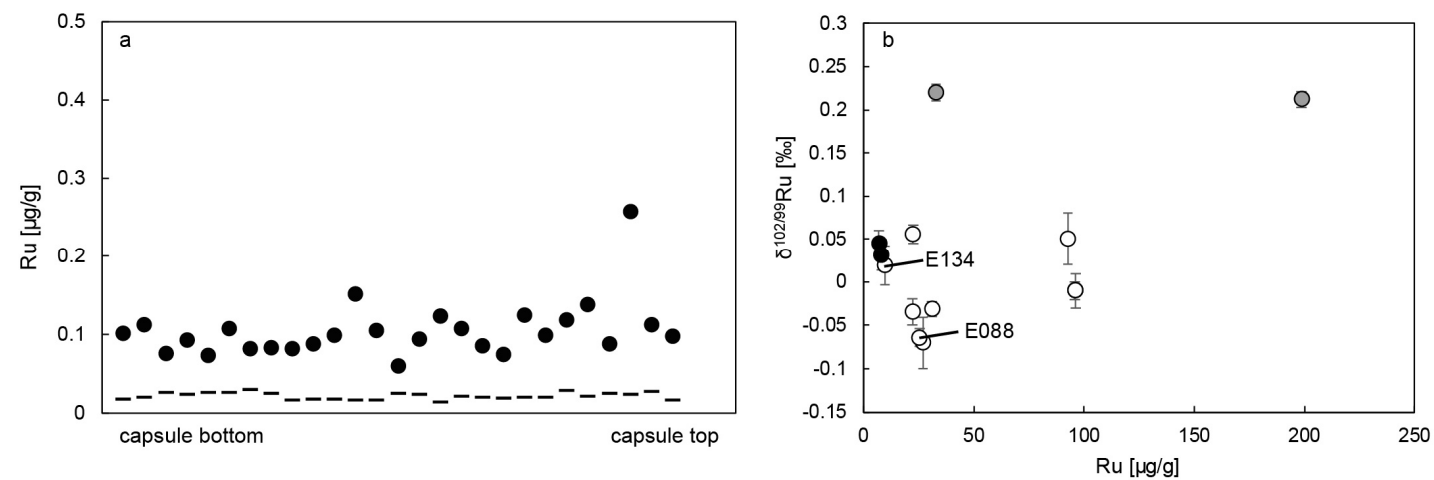

887

888

889

890

891

892

893

894

895

896

897

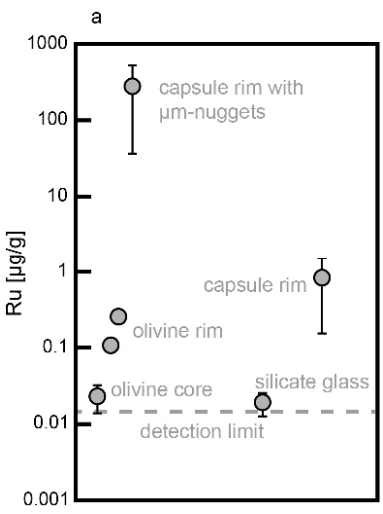

b

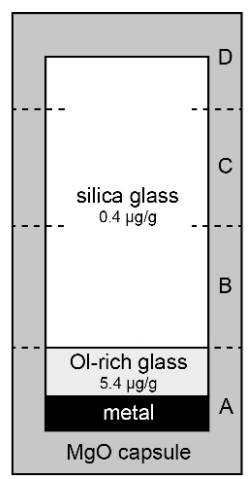

D $-0.28 \mu \mathrm{g} / \mathrm{g}$

C $-0.04 \mu \mathrm{g} / \mathrm{g}$

B - $0.18 \mu \mathrm{g} / \mathrm{g}$

A - $158 \mu \mathrm{g} / \mathrm{g}$

Figure 4: Ruthenium concentrations measured in run E135. SEM image of E135 can be is shown in

899 Figure 2c. a) While Ru concentrations measured by LA-ICPMS in the silicate glass and inside the

900 olivine crystals are low, Ru concentrations are elevated at the rim of the olivine phenocrysts and at

901 the olivine layer at the edge of the capsule. Concentrations in the MgO capsule were below the 
902 detection limit. This supports the assumption the Ru is concentrated in Ru-rich nuggets, which are

903 attached to the silicate glass-olivine interface. b) Sketch of experiment E135. The sample was

904 separated into 7 pieces, which were then separately analyzed with quadrupole ICPMS: metal, silicate

905 glass, ol-rich silicate glass, 4 (A-D) sections of the MgO capsule: The silicate glass was drilled out of

906 the capsule leaving a rest of glass that was attached to the capsule (section A-D). The "ol-rich" glass

907 (with olivine phenocrysts, SEM image in Figure 2c) and the glass attached to the capsule fragments $A$ -

$908 D$ show elevated Ru concentrations relative to the drilled-out silicate glass. This supports the

909 assumption that the Ru is concentrated in Ru-rich nuggets, which are attached to the silicate glass-

910 olivine interface.

911

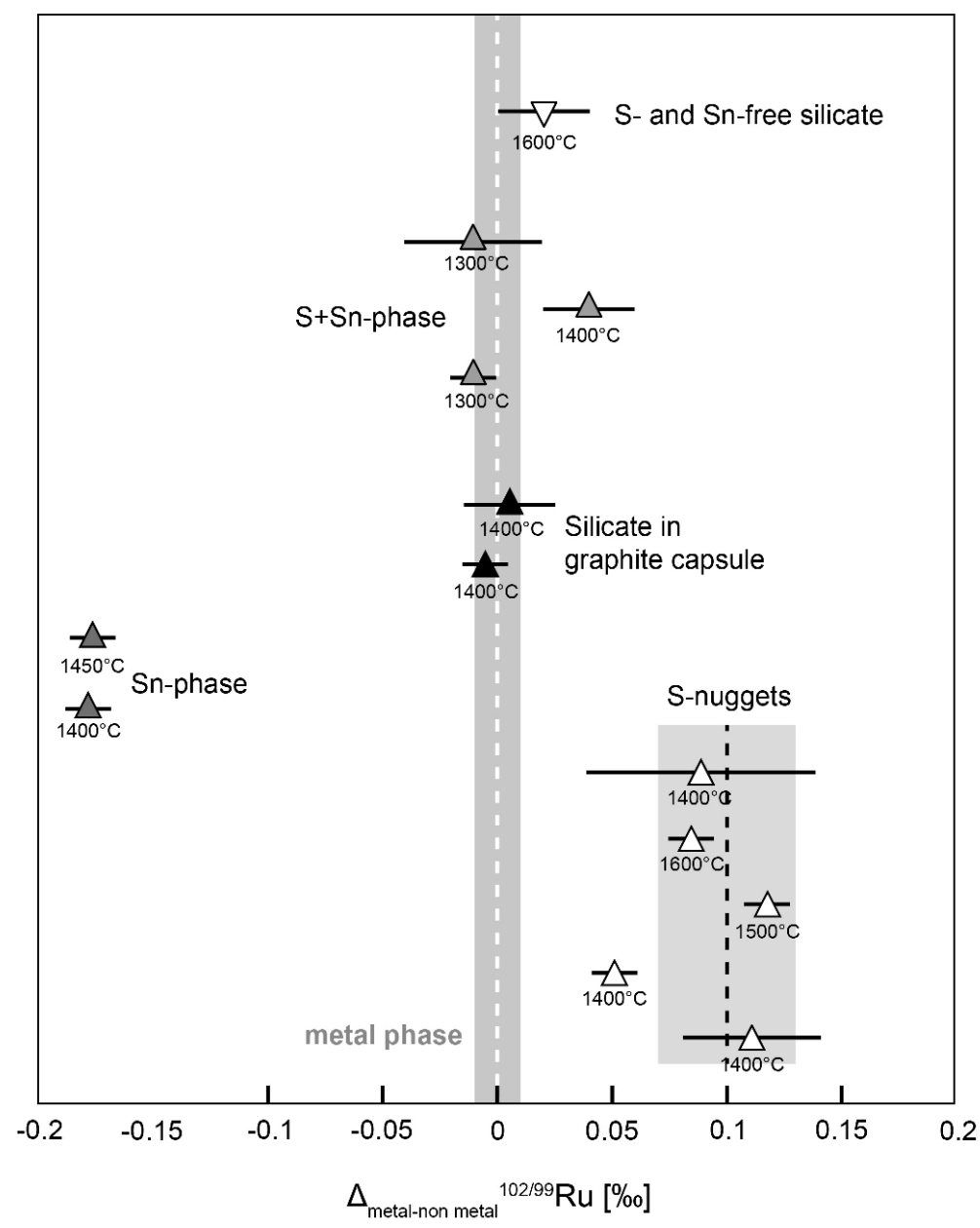

912 
913 Figure 5: Ruthenium stable isotope fractionation measured in silicate glasses. The $\delta^{102 / 99} R u$ analyses

914 from metal are normalized to zero; $\Delta^{102 / 99} \mathrm{Ru}$ metal-non metal $=\delta^{102 / 99} \mathrm{Ru}$ metal $-\delta^{102 / 99} \mathrm{Ru}$ non metal with non-

915 metal being either silicate glass, sulfide nanonuggets, or a Sn-phase. The fractionation is dependent

916 on the starting material composition, as Ru is either concentrated in S-nuggets or a Sn-bearing phase.

917 Runs in S-bearing systems show opposing isotope fractionation direction with Sn-bearing runs

918 resulting in an isotopically lighter $\delta^{102 / 99} \mathrm{Ru}$ signature for S-bearing runs. Sn-bearing experiments

919 indicate a heavier signature. In experiments with graphite capsules neither S nor Sn nuggets formed

920 and hence no isotope fractionation is observed.

921

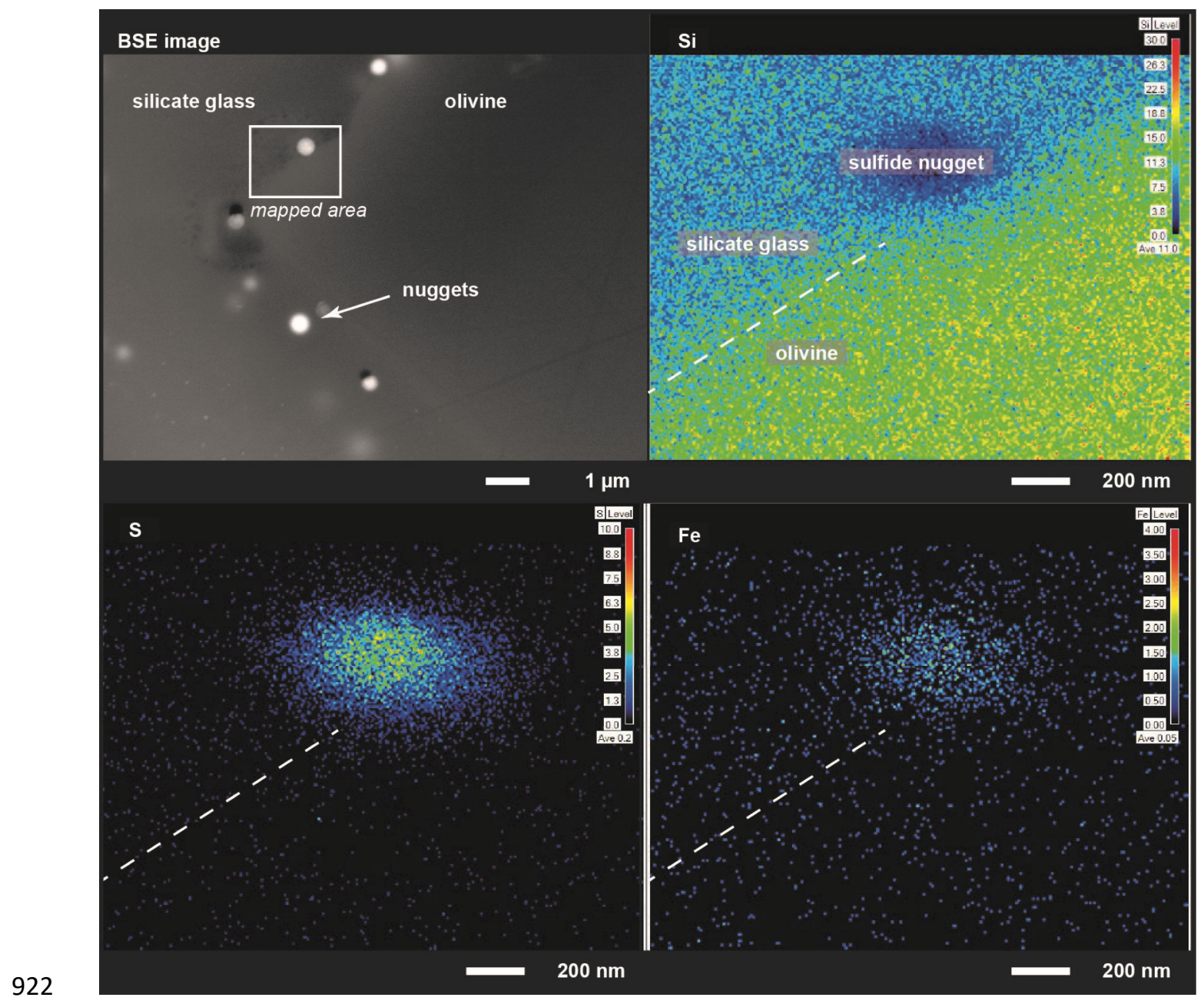


924 EPMA. The color scale on the element maps show relative abundances of the elements. The analyzed 925 nuggets are attached to the silicate glass-olivine interface and about 100-500 nm diameter. The white 926 dashed line indicates the silicate glass-olivine boundary.

927

928

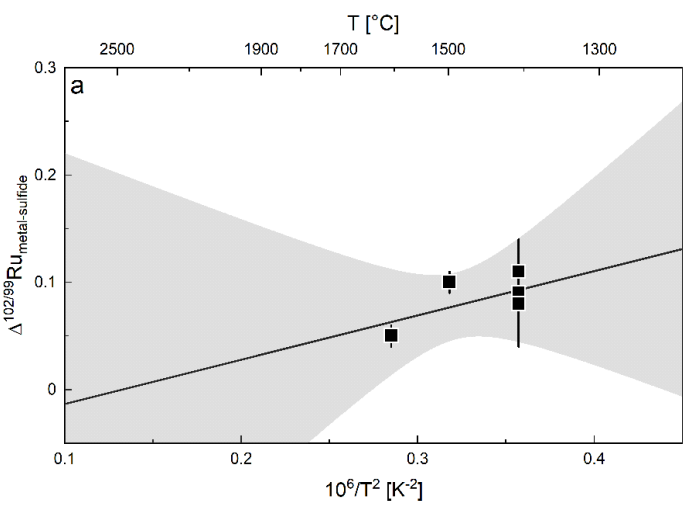$$
\text { ( }
$$

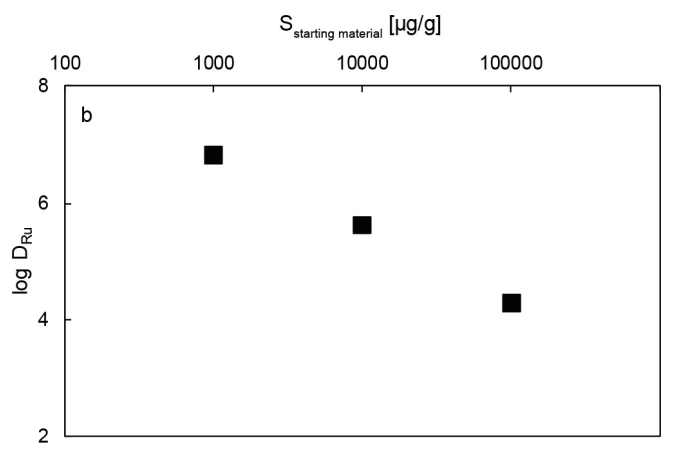

Figure 7: $D_{R u}$ vs. S concentrations a) in the silicate and b) in the metal portion of the starting material. Due to the presentation in logarithmic scale errors are covered within the size of the symbols. Data from Laurenz et al. (2016) are from experiments at $11 \mathrm{GPa}$ and $2373-2473{ }^{\circ} \mathrm{C}$. $D_{R u}$ increases with increasing $P$ and $T$, but increasing $S$ in the silicate makes $R u$ less siderophile.
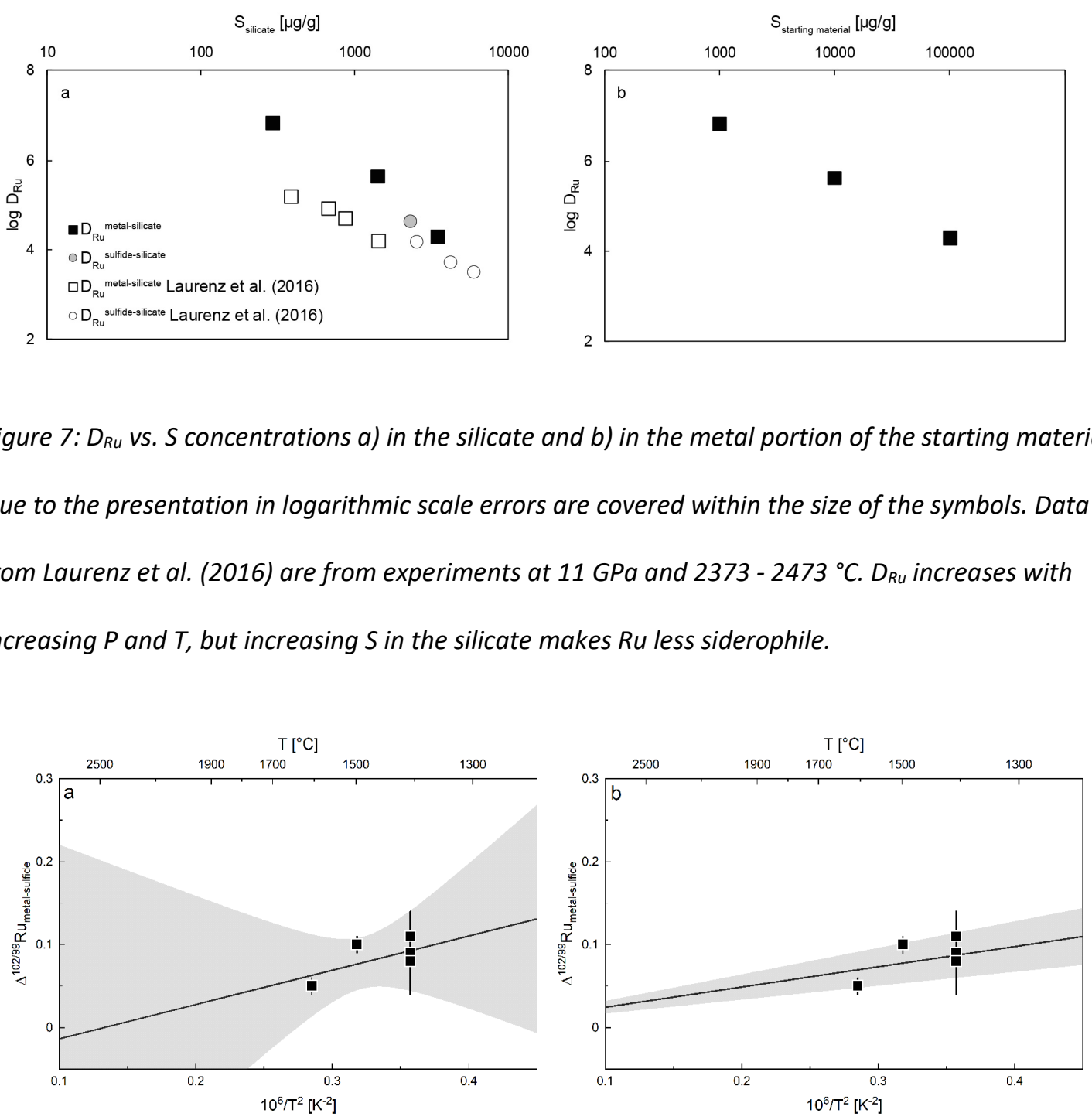

Figure 8: Approach for the temperature dependence of equilibrium Ru isotope fractionation between liquid metal and liquid sulfide (E088, E089, E097, E098, E102; Table 3). Error bars are the $95 \%$ confidence intervals of the respective analyses. a) The fit is fixed on the average value of the
934

935

936 
937 datapoints at $1400^{\circ} \mathrm{C}$ and supports the general assumption of a temperature dependency. The

938 temperature dependency of the fractionation factor would be $A=0.41( \pm 0.33) \times 10^{6}$ and is

939 represented by the solid line. b) This weighted best fit was determined by a best fit estimation using

940 the average value for the $1400{ }^{\circ} \mathrm{C}$ experiments and the $1600{ }^{\circ} \mathrm{C}$ experiment and is fixed to "zero". The

941 temperature dependency of the fractionation factor $A=0.24( \pm 0.03) \times 10^{6}$ is represented by the solid

942 line. The gray areas reflect the uncertainty (95\% confidence interval) of the fractionation factor ( \pm

$\left.9430.03 \times 10^{6}\right)$

944

945

946 Tables

947 Table $1 \quad$ Chemical composition (wt.\%) of silicate and metal starting mixtures.

948

Table $2 \quad$ Major element composition of silicate glasses and metal phases in wt.\% measured with

950

951

952

953

954

955

956

957

958

959
Table 3 Details of experimental run conditions, Ru contents and Ru isotopic compositions of run products. For some silicate samples the Ru concentrations were not only determined using bulk methods (MC-ICPMS), but also in-situ methods using LA-ICPMS. Partition coefficients (log $D_{R u}{ }^{\text {metal-silicate }}$ were calculated only for samples that were analyzed by LA-ICPMS. Capsule $C=$ graphite, $t=$ run duration in hours.

a Number of isotopic analysis. 
${ }^{b}$ Ruthenium concentrations of silicate glasses determined by LA-ICPMS. Uncertainties in parentheses are $1 \sigma$ of 5 to 15 spot analysis per sample.

${ }^{\mathrm{c}}$ Ruthenium concentrations determined from the double spike isotope ratio analyses. Uncertainties are $<1 \%$ including measurement uncertainties and weighing.

${ }^{d}$ Measured $\mathrm{Ru}$ isotope mass fractionation relative to an Alfa Aesar standard solution. Given uncertainties are $95 \%$ c.i. for samples with $\mathrm{N} \geq 4$.

e Isotopic difference of metal and silicate

${ }^{f}$ Partition coefficients $\mathrm{D}_{\mathrm{Ru}}{ }^{\text {metal-silicate }}$ calculated using LA-ICPMS concentration data of metals (Table 2) and silicates for selected experiments.

${ }^{\mathrm{g}}$ Isotopic difference of metal and silicate calculated using the average $\delta^{102 / 99} \mathrm{R} \mathrm{B}_{\text {Bulk }}$ of all analyzed metal phases representing the bulk isotopic composition as proven by the absence of any isotopic difference between starting material and metal phases.

\section{Supplementary Figures}

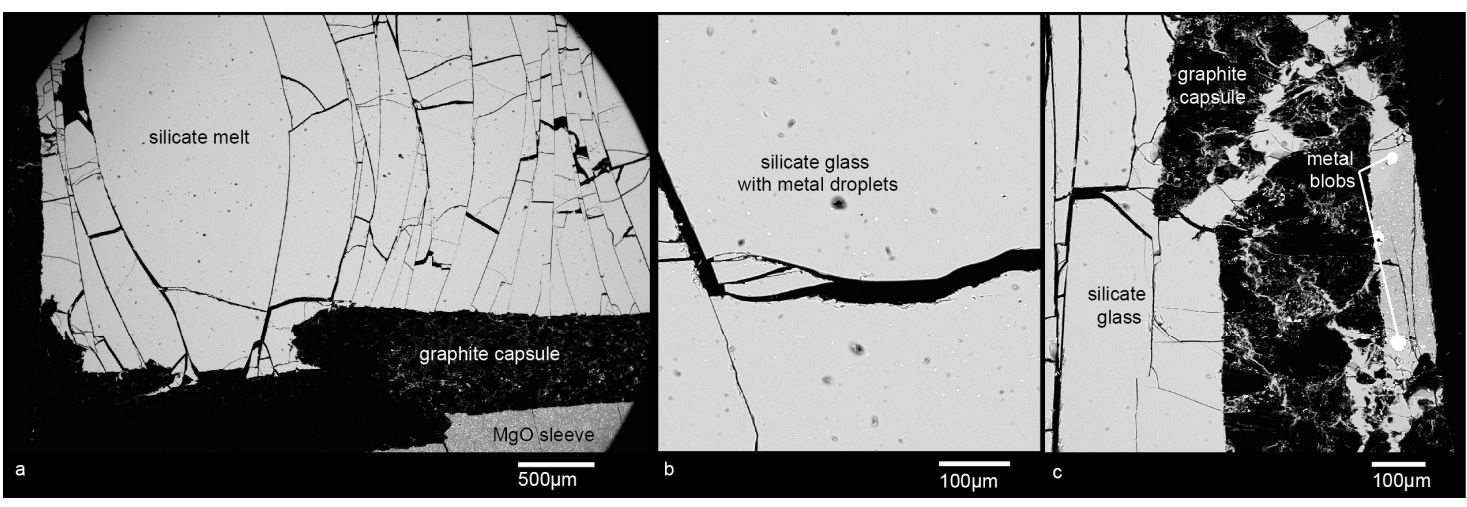

Supplementary Figure 1: Back-scattered electron (BSE) image of experiments E168. This experiment

was performed in a graphite capsule but could not be considered for further analyses. The metal phase was lost during preparation. a) The contact between graphite capsule and silicate glass shows no rection phase like olivine in MgO capsules. b) In E168 silicate glass contains a high amount of 
980 metal droplets that exsolved during quenching. Note that for successful runs in graphite capsule

981 (E115 and E141) Ru concentration in the silicate is extremely low (Table 3). c) At the bottom of the 982 capsule the melt partially infiltrates the the graphite capsule.

983 
Table 1: Chemical composition (wt.\%) of silicate and metal starting mixtures.

\begin{tabular}{cccccccc}
\hline & $\mathrm{SiO}_{2}$ & $\mathrm{Al}_{2} \mathrm{O}_{3}$ & $\mathrm{MgO}$ & $\mathrm{FeO}$ & $\mathrm{CaO}$ & $\mathrm{Na}_{2} \mathrm{O}$ & $\mathrm{K}_{2} \mathrm{O}$ \\
\hline Silicate & & & & & & & \\
M011 & 47 & 15 & 7 & 10 & 11 & 6.5 & 3.5 \\
\hline Metals & $\mathrm{Fe}$ & $\mathrm{Ru}$ & $\mathrm{Sn}$ & $\mathrm{S}$ & & & \\
M006 & 67 & 11 & 22 & - & & \\
M047 & 67 & 10 & 18 & 5 & & \\
M048 & 85 & 10 & - & 5 & & \\
M116 & 55 & 10 & - & 35 & & \\
M117 & 75 & 10 & - & 15 & & & \\
M133 & 90 & 10 & - & - & & & \\
\hline
\end{tabular}


Table 2: Major element composition of silicate glasses and metal phases in wt.\% measured with electron probe micro-analysis $\mathrm{E}$

\begin{tabular}{|c|c|c|c|c|c|c|c|c|}
\hline Run & $\mathrm{Na}_{2} \mathrm{O}$ & $\mathrm{MgO}$ & $\mathrm{SiO}_{2}$ & $\mathrm{Al}_{2} \mathrm{O}_{3}$ & $\mathrm{~K}_{2} \mathrm{O}$ & $\mathrm{CaO}$ & $S$ & $\mathrm{SnO}_{2}$ \\
\hline \multicolumn{9}{|l|}{ Silicates } \\
\hline E102 & $3.7(2)$ & $36.4(2)$ & $33.7(6)$ & $11.6(4)$ & $2.5(1)$ & $6.8(2)$ & b.d. & b.d. \\
\hline E017 & $5.9(1)$ & $12.6(6)$ & $45.7(2)$ & $15.3(3)$ & $3.5(1)$ & $10.0(2)$ & b.d. & b.d. \\
\hline E110 & $5.8(1)$ & $9.9(3)$ & $47.4(2)$ & $15.3(2)$ & $3.2(1)$ & $9.5(1)$ & b.d. & b.d. \\
\hline E135 & $6.4(3)$ & $12.3(3)$ & $43.1(3)$ & $14.7(3)$ & $3.1(1)$ & $10.6(2)$ & b.d. & b.d. \\
\hline E029 & $5.1(2)$ & $14.3(8)$ & $45(1)$ & $15.2(3)$ & $3.0(1)$ & $10.4(2)$ & $0.6(1)$ & $0.41(4)$ \\
\hline E031 & $5.2(1)$ & $15.2(7)$ & $44.0(4)$ & $15.1(1)$ & $3.12(6)$ & $10.0(3)$ & b.d. & b.d. \\
\hline E104 & $5.8(3)$ & $7.5(2)$ & $47.6(4)$ & $15.2(1)$ & $3.4(1)$ & $9.4(2)$ & b.d. & b.d. \\
\hline E109 & $4.9(2)$ & $15.7(6)$ & $47.6(3)$ & 13.6(7) & $2.9(1)$ & $7.3(1)$ & b.d. & b.d. \\
\hline E134 & $4.0(1)$ & $33.8(4)$ & $34.4(8)$ & $12.1(6)$ & $2.5(1)$ & $7.0(3)$ & b.d. & b.d. \\
\hline E175 & $6.0(2)$ & $7.3(3)$ & $47.0(4)$ & $15.3(4)$ & $3.2(1)$ & $9.9(2)$ & $0.4(2)$ & b.d. \\
\hline \multirow[t]{2}{*}{ E041 } & $5.6(1)$ & $13.9(2)$ & $43.9(3)$ & $14.8(2)$ & $3.3(1)$ & $9.6(1)$ & $0.23(3)$ & $0.18(5)$ \\
\hline & $\mathrm{Fe}$ & $\mathrm{Si}$ & $S$ & Sn & $\mathrm{Ru}$ & Total & $\mathrm{f}\left(\mathrm{O}_{2}\right) \Delta \mathrm{IW}$ & \\
\hline \multicolumn{9}{|l|}{ Metals } \\
\hline \multicolumn{2}{|c|}{ E017 66.7(7) } & $0.06(1)$ & b.d. & $22.9(7)$ & $11.3(2)$ & 101.0(3) & -1.86 & \\
\hline \multicolumn{2}{|c|}{ E135 81.4(8) } & b.d. & $4(1)$ & b.d. & $14.0(8)$ & $99.4(8)^{*}$ & -1.86 & \\
\hline \multicolumn{2}{|c|}{ E031 67.4(9) } & $0.05(1)$ & $0.9(2)$ & $21(1)$ & $10.8(2)$ & $100.6(4)$ & -2.05 & \\
\hline \multicolumn{2}{|c|}{ E175 84.2(1) } & b.d. & $1.4(1)$ & b.d. & $13.9(3)$ & $99.5(3)^{*}$ & -1.47 & \\
\hline \multicolumn{2}{|c|}{ E041 metal 56.2(8) } & $0.05(5)$ & $5.8(3)$ & $24(1)$ & $13.6(2)$ & $100.5(2)$ & & \\
\hline \multicolumn{2}{|c|}{ E041 sulfide $64.0(8)$} & $0.01(1)$ & $27(1)$ & $6(1)$ & $0.7(2)$ & $98.2(2)$ & & \\
\hline
\end{tabular}


PMA. Uncertainties (1 s.d.) are given in parentheses showing the first significant digit. b.d. = below detection limit. Totals indicated with * wer€

\begin{tabular}{cc} 
FeO & Total \\
\hline $5.3(2)$ & $100.0(6)^{*}$ \\
$6.4(1)$ & $99.5(4)$ \\
$9.0(2)$ & $100.1(3)^{*}$ \\
$9.9(2)$ & $100.1(3)^{*}$ \\
$3.0(1)$ & $97(1)$ \\
$5.5(2)$ & $98.3(4)$ \\
$11.2(3)$ & $100.1(4)^{*}$ \\
$8.0(3)$ & $100.0(7)^{*}$ \\
$6.3(2)$ & $100.1(8)^{*}$ \\
$10.9(9)$ & $100.0(9)^{*}$ \\
$6.6(1)$ & $98.3(4)$ \\
\hline &
\end{tabular}


: determined by energy-dispersive X-ray analysis (EDX) only. 
Table 3: Details of experimental run conditions, Ru contents and Ru isotopic compositions of run products. For some silicate samples the Ru c

\begin{tabular}{|c|c|c|c|c|c|c|c|c|}
\hline Sample & start mixtures & $\mathrm{T}\left[{ }^{\circ} \mathrm{C}\right]$ & $t(h)$ & Capsule & Dopant & $\mathrm{N}^{\mathrm{a}}$ & $\mathrm{Ru}_{\text {LA-ICPMS }}[\mathrm{ppm}]^{\mathrm{b}}$ & $\mathrm{Ru}_{\mathrm{MC}-\mathrm{ICPMS}}[\mathrm{p}$ \\
\hline \multicolumn{9}{|l|}{ Starting material } \\
\hline Alfa Aesar Ru metal & & & & & & 4 & & \\
\hline \multicolumn{9}{|l|}{ Metals } \\
\hline E088 M & M048 & 1400 & 3 & $\mathrm{MgO}$ & $\mathrm{s}$ & 7 & & \\
\hline E089 M & M048 & 1400 & 3 & $\mathrm{MgO}$ & $\mathrm{s}$ & 7 & & \\
\hline E097 M & M048 & 1500 & 3 & $\mathrm{MgO}$ & $\mathrm{s}$ & 8 & & \\
\hline E102 M & M048 & 1600 & 3 & $\mathrm{MgO}$ & $\mathrm{s}$ & 6 & & \\
\hline E110 M & M006 & 1400 & 3 & $\mathrm{MgO}$ & Sn & 5 & & \\
\hline E126 M & M006 & 1450 & 3 & MgO & Sn & 5 & & \\
\hline E128 M & M048 & 1300 & 3 & $\mathrm{MgO}$ & $S+S n$ & 5 & & \\
\hline E104 M & M047 & 1300 & 3 & $\mathrm{MgO}$ & $S+S n$ & 5 & & \\
\hline E109 M & M047 & 1400 & 3 & $\mathrm{MgO}$ & $S+S n$ & 5 & & \\
\hline E134 M & M133 & 1600 & 3 & $\mathrm{MgO}$ & - & 5 & & \\
\hline E115 M & M048 & 1400 & 3 & C & S & 5 & & \\
\hline Average (bulk) & & & & & & (11) & & \\
\hline \multicolumn{9}{|l|}{ Silicates } \\
\hline E088 S & M048 & 1400 & 3 & $\mathrm{MgO}$ & S & 5 & & 26.93 \\
\hline E089 S & M048 & 1400 & 3 & $\mathrm{MgO}$ & S & 7 & & 22.23 \\
\hline E098 S & M048 & 1400 & 6 & $\mathrm{MgO}$ & s & 5 & & 13.70 \\
\hline Average & & 1400 & 3 & $\mathrm{MgO}$ & $S$ & & & \\
\hline E097 S & M048 & 1500 & 3 & $\mathrm{MgO}$ & S & 6 & & 25.44 \\
\hline E0102 S & M048 & 1600 & 3 & $\mathrm{MgO}$ & S & 5 & $0.03(1)$ & 95.90 \\
\hline E110 S & M006 & 1450 & 3 & $\mathrm{MgO}$ & Sn & 5 & $0.3(1)$ & 32.84 \\
\hline E126 S & M006 & 1450 & 3 & $\mathrm{MgO}$ & Sn & 5 & & 198.7 \\
\hline E104 S & M047 & 1300 & 3 & $\mathrm{MgO}$ & $S+S n$ & 5 & $0.5(1)$ & 92.77 \\
\hline E109 S & M047 & 1400 & 3 & MgO & $S+S n$ & 5 & $0.02(1)$ & 96.23 \\
\hline E128 S & M048 & 1300 & 3 & $\mathrm{MgO}$ & $S+S n$ & 5 & & 22.47 \\
\hline E134 S & M133 & 1600 & 3 & $\mathrm{MgO}$ & - & 5 & $0.02(1)$ & 9.790 \\
\hline
\end{tabular}




\begin{tabular}{|c|c|c|c|c|c|c|c|c|}
\hline E115 S & M048 & 1400 & 3 & C & $S$ & 5 & & 8.207 \\
\hline E141 S & M048 & 1400 & 3 & C & $\mathrm{s}$ & 5 & & 7.015 \\
\hline \multicolumn{9}{|l|}{ LA-ICPMS only } \\
\hline E017 & M006+M011 & & 3 & & & & $0.13(6)$ & \\
\hline E135 & M048 & & 3 & & & & $0.02(1)$ & \\
\hline E029 & M006+0.01 wt.\% S & & 3 & & & & $8(7)$ & \\
\hline E041 & M006+1 wt.\% S & & 3 & & & & $0.16(7)$ & \\
\hline E041 (sul-sil) & M006+1 wt.\% S & & 3 & & & & $0.16(7)$ & \\
\hline E031 & M006+1 wt.\% S & & 3 & & & & $0.3(5)$ & \\
\hline
\end{tabular}

${ }^{a}$ Number of isotopic analysis.

${ }^{b}$ Ruthenium concentrations of silicate glasses determined by LA-ICPMS. Uncertainties in parentheses are calculated ... of 5 to 15 spot analysis ${ }^{\mathrm{C}}$ Ruthenium concentrations determined from the double spike isotope ratio analyses. Uncertainties are $<1 \%$ including measurement uncertai ${ }^{d}$ Measured Ru isotope mass fractionation relative to an Alfa Aesar standard solution. Given uncertainties are $95 \%$ c.i. for samples with $\mathrm{N} \geq 4$.

${ }^{\mathrm{e}}$ Isotopic difference of metal and nonmetal, which would be depending on the dopant either silicate (no dopant), sulfide (s), a Sn-rich phase ( ${ }^{f}$ Partition coefficients $D_{R u}{ }^{\text {metal-silicate }}$ calculated using LA-ICPMS concentration data of metals (Table 2) and silicates for selected experiments. 
:oncentrations were not only determined on the bulk sample (MC-ICPMS), but also in-situ using LA-ICPMS. Partition coefficients (log DRumetal-silicate were $\delta^{102} /{ }^{99} \mathrm{Ru}^{\mathrm{d}} \quad \Delta^{102 / 99} \mathrm{Ru}_{\text {nonmetal-metal }} \log _{\mathrm{Ru}}^{\text {metal-silicate } \mathrm{f}}$

$0.03 \pm 0.02$

$0.04 \pm 0.01$

$0.02 \pm 0.02$

$0.05 \pm 0.02$

$0.07 \pm 0.02$

$0.04 \pm 0.02$

$0.03 \pm 0.02$

$0.05 \pm 0.01$

$0.04 \pm 0.02$

$0.03 \pm 0.01$

$0.03 \pm 0.01$

$0.04 \pm 0.02$

$0.04 \pm 0.01$

$-0.07 \pm 0.03$

$-0.03 \pm 0.01$

$0.11 \pm 0.03$

$-0.05 \pm 0.05$

$0.08 \pm 0.01$

$0.09 \pm 0.05^{9}$

$0.09 \pm 0.03$

$-0.06 \pm 0.01 \quad 0.10 \pm 0.01$

$-0.01 \pm 0.01 \quad 0.05 \pm 0.01$

$0.22 \pm 0.01 \quad-0.18 \pm 0.01$

$0.21 \pm 0.01 \quad-0.17 \pm 0.01$

$0.05 \pm 0.03 \quad-0.01 \pm 0.03$

$-0.01 \pm 0.02 \quad 0.05 \pm 0.02$

$0.06 \pm 0.01 \quad-0.02 \pm 0.01$

$0.02 \pm 0.02 \quad 0.02 \pm 0.02$ 
$0.03 \pm 0.02$

$0.01 \pm 0.02$

$0.05 \pm 0.01$

$0.00 \pm 0.01$

5.9(2)

6.8(3)

2.0(1)

5.6(2)

4.6(2)

$5.5(2)$

; per sample.

inties and weighing.

(Sn) or a combination of Sn-rich phase and sufide (S+Sn) 
calculated for samples analyzed by LA-ICPMS only. Capsule $\mathrm{C}=$ graphite, $\mathrm{t}=$ run duration in hours . 